\title{
Experimental investigation on the effect of wear flat inclination on the cutting response of a blunt tool in rock cutting
}

\author{
Iman Rostamsowlat • Thomas Richard . \\ Brian Evans
}

Received: date / Accepted: date

\begin{abstract}
A vast majority of experimental research focuses on the cutting action of a sharp cutter while there has been limited experimental work devoted to the study of the contact process at the wear flat-rock interface. The specific objective of this study is to determine the effect of the wear flat inclination angle $(\beta)$ with respect to the cutter velocity vector $(\boldsymbol{v})$ on both the contact stress $(\sigma)$ and friction coefficient $(\mu)$ mobilized at the wear flat-rock interface. An extensive and comprehensive set of cutting experiments was carried out on thirteen different sedimentary quarry rock samples using a state-of-the-art rock cutting equipment. A unique cutter holder was purposely designed and manufactured along with a precise experimental protocol implemented in order to change the back rake angle and therefore the inclination $\beta$ by steps of $0.10^{\circ}$. The experimental observations confirm the existence of three regimes of frictional contact (identified as elastic, elasto-plastic and plastic) for all rock samples. Further, the results suggest that the scaled contact stress is predominantly controlled by a dimensionless number $\eta=\frac{E^{*} \tan \beta}{q}$ with $E^{*}$ the plane strain elastic modulus and $q$ the rock strength.
\end{abstract}

Keywords Rock cutting · Frictional contact · Wear flat inclination angle . Contact stress · Friction coefficient

Iman Rostamsowlat

Deep Exploration Technologies CRC, Department of Petroleum Engineering, Curtin University, Kensington, WA 6151, Australia

E-mail: iman.rostamsowlat@postgrad.curtin.edu.au, iman.rostamsowlat@gmail.com

Thomas Richard

Epslog SA, Rue Hocheporte 76, 4000 Liège, Belgium

Department of Petroleum Engineering, Curtin University, Australia

Brian Evans

Department of Petroleum Engineering, Curtin University, Australia 


\section{List of symbols}

$F \quad$ Total force acting on the cutter

$F_{c}, F_{f} \quad$ Total cutting and frictional-contact forces

$F_{c n}, F_{c s} \quad$ Normal and tangential components of the cutting force

$F_{f n}, F_{f s} \quad$ Normal and tangential components of the frictional-contact force

$\widetilde{F_{f n}}, \tilde{F_{f s}} \quad$ Projected components of the contact force components

$d \quad$ Depth of cut

$A_{c} \quad$ Cross-sectional area of groove traced by cutter

$A_{f} \quad$ Wear flat area

$\omega \quad$ Width of cutter

$q \quad$ Uni-axial compressive strength of the rock material

$\zeta \quad$ Ratio of normal component to tangential component of cutting force

$\varepsilon \quad$ Intrinsic specific energy

$\theta \quad$ Back rake angle

$\theta_{*} \quad$ Initial back rake angle

$\Delta \theta_{*} \quad$ Relative increment of back rake angle

$\psi \quad$ Interfacial friction angle

$\boldsymbol{v} \quad$ Horizontal cutting velocity

$\phi \quad$ Friction angle

$\mu \quad$ Friction coefficient

$\sigma \quad$ Normal contact stress

$\ell \quad$ Length of wear flat surface

$\beta \quad$ Inclination angle of wear flat with respect to velocity vector

$E \quad$ Elastic modulus of the rock material

$\nu \quad$ Poisson's ratio of the rock material

$\varphi \quad$ Internal friction angle of the rock material

$\prod \quad$ Scaled contact stress

$\eta \quad$ Dimensionless number

$\chi \quad$ Chamfer angle

$\Delta z \quad$ Relative vertical displacement of spindle

\section{Introduction}

Rock cutting has been the subject of research for nearly 60 years and gaining a better understanding of this process has been one of the main objectives of drilling research since the 1950s. In the early 1970s, the introduction of Polycrystalline Diamond Compact (PDC) by General Electric (GE) created a breakthrough in the oil and gas drilling industry $[10,47,7]$. As a consequence, about $60 \%$ of the drilling operations for the exploration and production of hydrocarbons are presently conducted with PDC bits [35, 7]. A PDC bit consists of a matrix (tungsten carbide metallurgically bonded with a metallic binder) or steel body that is covered with inserts often referred to as PDC cutters which are made of a thin layer of synthetic polycrystalline diamond bonded on a tungsten carbide substrate. Cutters are distributed on the bit face often 
along distinctive blades, their location but also orientation in the space are essential features of the design $[32,22,45,3,4]$, see Fig. 1.

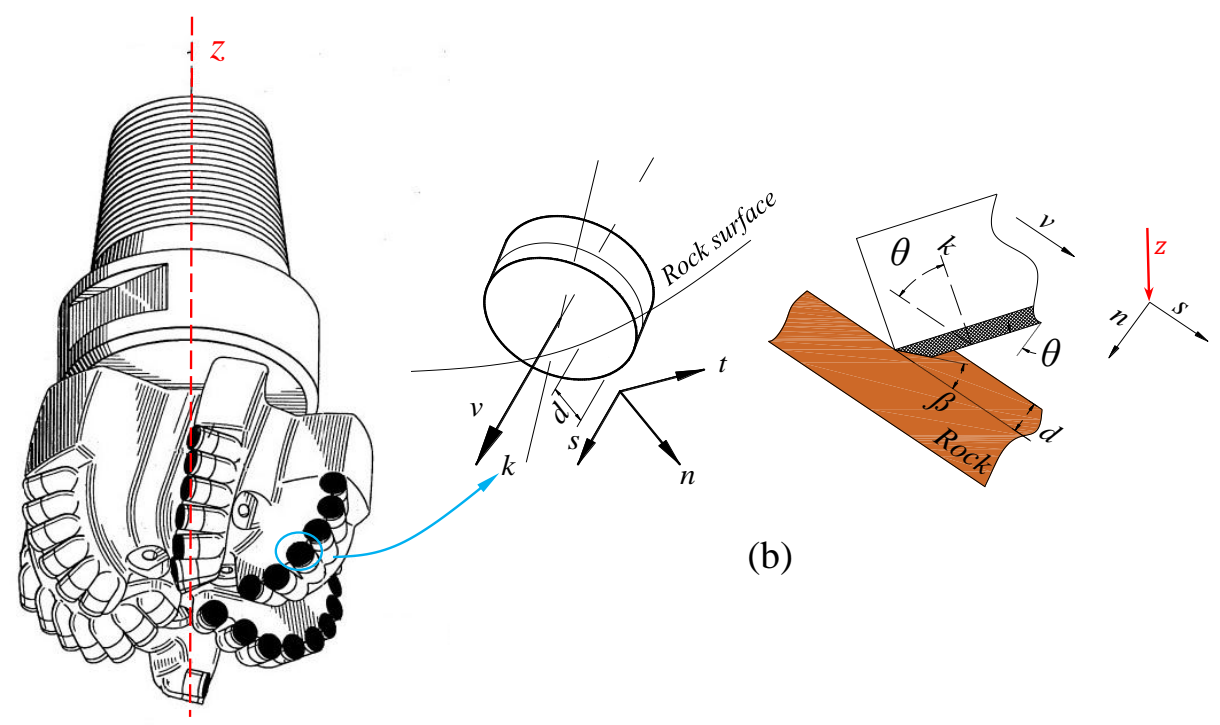

(a)

Fig. 1: (a) 3D drawing of a PDC bit (updated from [36]), and (b) sketches of a worn cutter tracing a groove of depth $d$ on the bottom-hole. The angle $\beta$ is the angle between the cutter wear surface and the cutter linear velocity $(v)$.

Despite continuous improvement in abrasion, impact and fatigue characteristics of PDC cutters, drilling is still commonly accompanied by the development of a wear surface or wear flat on the inserts, see Fig. 2, which affects the cutting efficiency and thus the drilling performance [25, 49]. The development of wear surfaces reduces the bit aggressiveness, meaning that under similar axial force (or weight on bit WOB), the resulting rate of penetration (ROP) reduces. As wear develops, maintaining the rate of penetration requires three to eight times as much WOB as when the bit was sharp [12]. Therefore, modeling the drilling response of PDC bits relies upon a proper understanding of the response of a single worn (blunt) cutter. Under conditions of constant rate of penetration (ROP) and angular velocity $(\Omega)$, each individual cutter follows an helicoidal trajectory tracing a groove of depth $(d)$ on the bottom hole surface [38], see Fig. 1. 


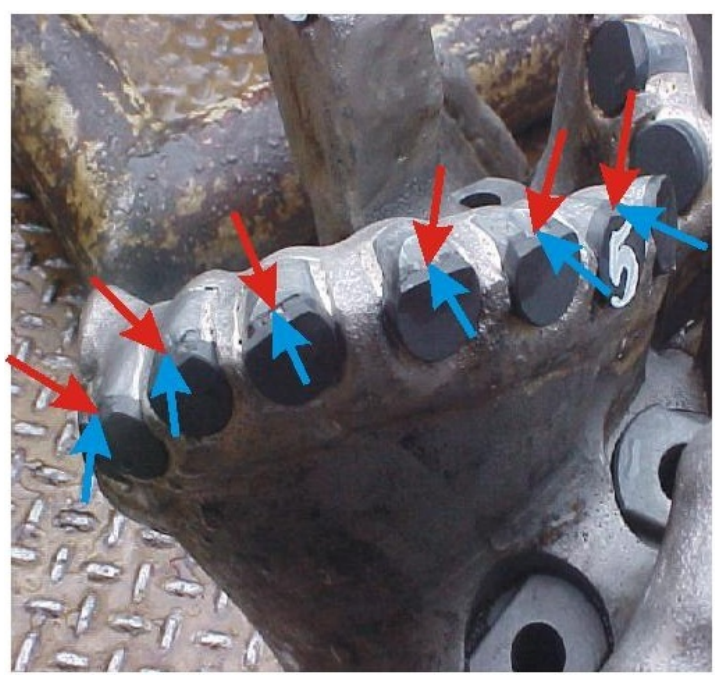

Fig. 2: Worn PDC drag bit.

It is commonly accepted that the resultant cutting force acting on the insert is controlled, for given rock mechanical properties, by the geometry of the groove being traced, the cutter orientation and in particular, the cutter forward inclination or back rake angle $(\theta)$ and the extent of the cutter state of wear (size of the wear surface) $[16,14,41,45]$. However, the effect of inclination angle $(\beta)$ between the wear flat and the cutter velocity vector is rarely accounted for. Results of numerical simulations by Zhou \& Detournay [51] and a few experimental investigations $[20,21,8]$ suggest that small variations of the inclination angle between $0^{\circ}$ and $3^{\circ}$ can lead to a large variation of the contact stress $(\sigma)$ mobilized across the wear flat surface. The main objective of this paper is to investigate experimentally how the inclination angle $(\beta)$ affects the cutting response of a single blunt cutter tracing a groove on the surface of a rock sample. For this purpose, novel cutting experiments were carried out on thirteen different sedimentary rocks with a unique experimental setup allowing for a precise adjustment and control of the angle $\beta$ with a precision of about $0.10^{\circ}$ over a range varying from $-5^{\circ}$ to $15^{\circ}$.

\section{Rock cutting}

It is commonly agreed in the literature $[9,23,17,48,19,55]$ that the cutting action of a blunt (worn) bit or cutter can be divided into two independent processes: $(i)$ a pure cutting action in front of the cutting face, and (ii) a frictional contact mobilized across the wear flat. The total force $(\mathbf{F})$ acting on a single cutter is then written as the sum of two forces, $\mathbf{F}_{\mathbf{c}}$ and $\mathbf{F}_{\mathbf{f}}$ which 
coexist and are associated with the pure cutting (subscript $c$ ) and frictional contact processes (subscript $f$ ), respectively (Eq. 1).

$$
\mathbf{F}=\mathbf{F}_{\mathbf{c}}+\mathbf{F}_{\mathbf{f}}
$$

The pure cutting process is commonly studied by carrying out cutting experiments with sharp cutting tools, see Fig. 3a. The process is often described as either a ductile process (plastic failure) or a brittle process (propagation of fractures) depending on the depth of cut $(d)[42,52,33,53,34,50]$. Models used in the industry implicitly consider that a ductile regime of failure is dominant and that the work performed by the cutter is proportional to the volume of rock being removed, which leads to a linear relationship between the pure cutting force $\left(F_{c}\right)$ and the cross-sectional area $\left(A_{c}\right)$ of the groove traced by the cutter $[39,11]$. As shown in Fig. 3a, the two force components $F_{c n}$ and $F_{c s}$ (which is associated with the pure cutting), normal (subscript $n$ ) and parallel (subscript $s$ ) to the velocity vector $\boldsymbol{v}$, respectively, can be written as [17]:

$$
\left\{\begin{array}{c}
F_{c n}=\zeta \varepsilon A_{c} \\
F_{c s}=\varepsilon A_{c}
\end{array}\right.
$$

where $\varepsilon$ is the intrinsic specific energy that is found well correlated with the uni-axial compressive strength of the rock [40,42, 46, 45, 54, 29,37], $A_{c}$ is the cross-sectional area of the groove traced by the cutter $\left(A_{c}=\omega \times d\right.$ for a rectangular shaped cutter where $\omega$ is the width of the cutter) and the number $\zeta(\zeta=\tan (\theta+\psi))$ is simply the ratio of normal to horizontal components of the cutting force where $\psi$ is the interfacial friction angle and $\theta$ is the back rake angle (positive when inclined forward).

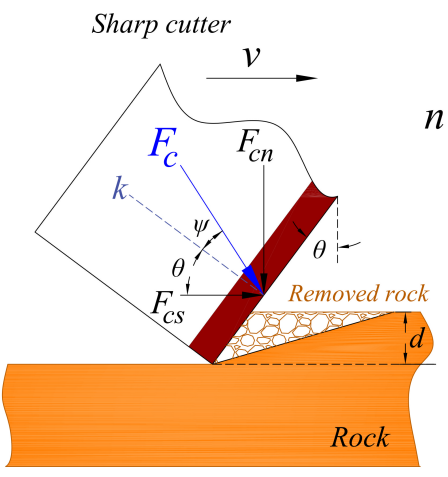

(a)

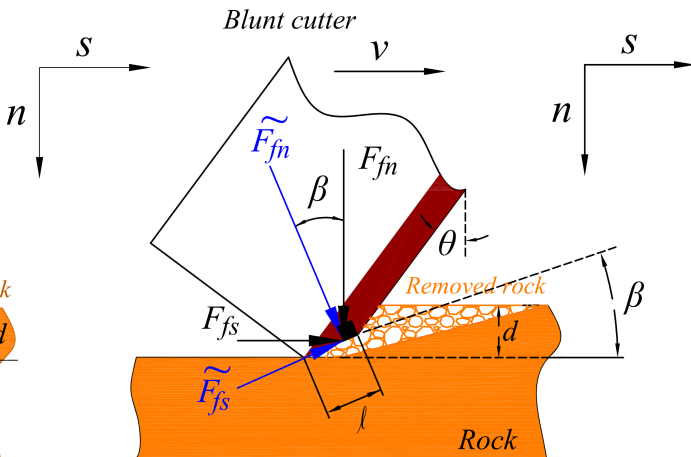

(b)

Fig. 3: Forces acting on (a) a sharp PDC cutter, and (b) a blunt PDC cutter. 
For a wear flat inclined by an angle $\beta$, the total frictional force vector $\left(\mathbf{F}_{\mathbf{f}}\right)$ acting on the wear flat surface (Fig. 3b) can also be decomposed into normal $\left(\mathbf{F}_{\mathbf{f n}}\right)$ and tangential $\left(\mathbf{F}_{\mathbf{f s}}\right)$ components. The contact stress and friction coefficient then read:

$$
\begin{gathered}
\sigma(d)=\frac{F_{f n} \cos \beta+F_{f s} \sin \beta}{\omega \ell}=\frac{\tilde{F_{f n}}}{A_{f}} \\
\mu(d)=\frac{\tilde{F_{f s}}}{\tilde{F_{f n}}}
\end{gathered}
$$

where $A_{f}$ is the wear flat area (for a rectangular cutter $A_{f}=\omega \times \ell$ with $\ell$ as the length of wear flat surface) and the force components projected on the normal $\left(\tilde{F_{f n}}\right)$ and tangent $\left(\tilde{F_{f s}}\right)$ to the wear flat surface are given as:

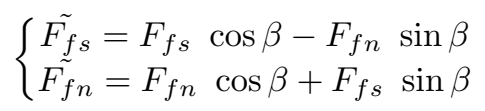

where

$$
\left\{\begin{array}{l}
F_{f s}(d, \theta)=F_{s}(d, \theta)-F_{c s}(d, \theta) \\
F_{f n}(d, \theta)=F_{n}(d, \theta)-F_{c n}(d, \theta)
\end{array}\right.
$$

with $F_{f}(d, \theta)$ the force measured on a blunt cutter for a given depth of cut $(d)$ and back rake angle $(\theta)$, and $F_{c}(d, \theta)$ the force measured on a sharp cutter for the same depth of cut and back rake angle.

Experimental results reveal three distinct phases in the cutting response of a worn cutter (or drilling response of a drag bit) with respect to the depth of cut $(d)[18,8,15,31]$, see Fig. 4 . At shallow depth of cut (phase I), it is assumed that the two contacting surfaces (the cutter wear flat and the rock surfaces) are not entirely conforming, and an increase in the depth of cut leads to an increase in both the cutting force associated with the pure cutting process but also in the effective contact area $\left(A_{f}\right)$, up to a critical depth of cut $\left(d<d_{*}\right)$. In phase II $\left(d_{*} \leq d \leq d_{* *}\right)$, the effective contact area has reached a limit value $\left(A_{f}=A_{f *}\right)$, and the incremental drilling-cutting response is governed by the pure cutting process [18]. On a drill bit, phase III is marked by the occurrence of additional contact between the rock and bit body when an excess of cuttings is not efficiently flushed away from the bit face. 


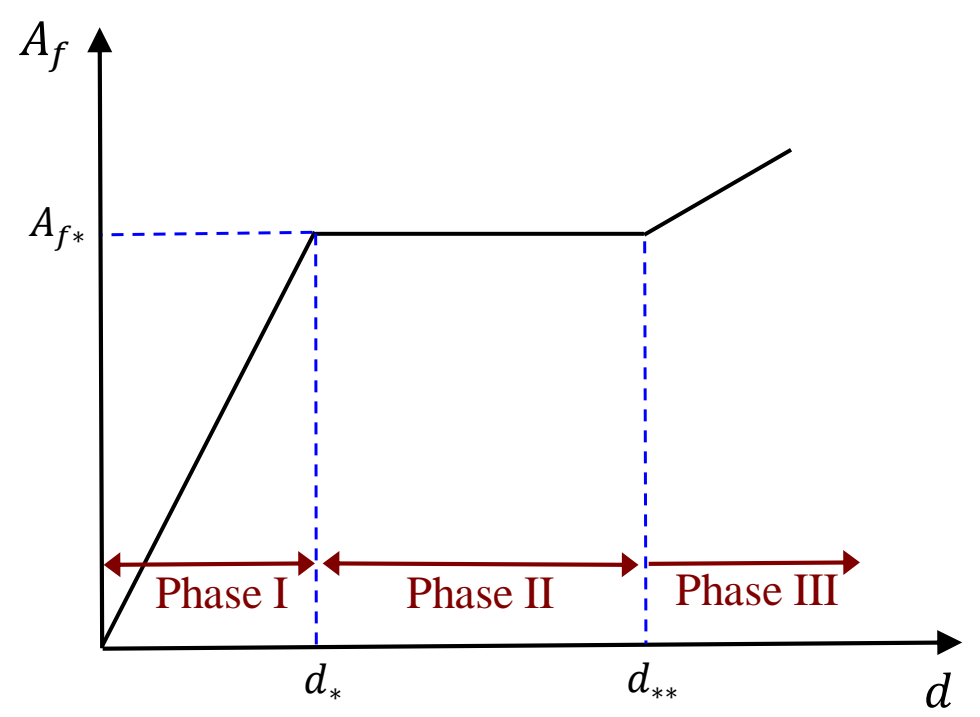

Fig. 4: Conceptual Evolution of contact area $\left(A_{f}\right)$ with depth of cut $(d)$ for a blunt cutter.

The response of a blunt cutter in a space force-depth of cut is illustrated in Fig. 5. The extent of phase $\mathrm{I}$ is controlled by the size of the wear surface and the angle $\beta[18,43]$; in phase II, the response is parallel to the response of a sharp cutter $[6,1,15]$. 


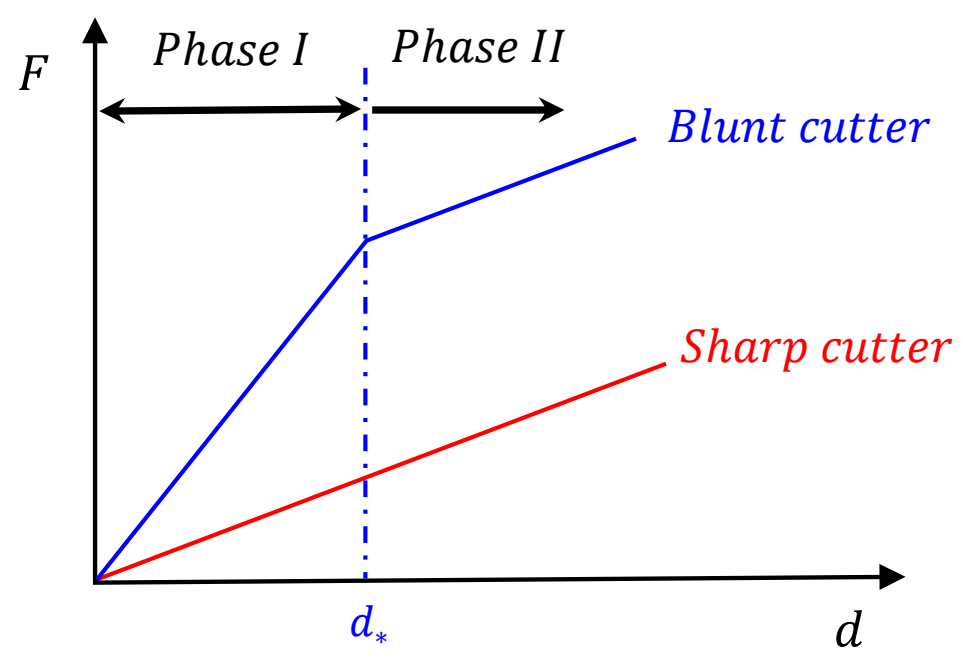

Fig. 5: Conceptual plot of force against depth of cut for both a sharp cutter and a blunt cutter.

Experimental results indicate that the contact stress $(\sigma)$ at the wear flatrock interface for an inclination angle of a few degrees $\left(\beta \simeq 2^{\circ}-3^{\circ}\right)$ is comparable in magnitude to the uni-axial compressive strength $(q)$ of the rock $[6,1,31,15,18,30]$. Results also show that the friction angle $(\phi)$ mobilized at the wear flat-rock interface is comparable with the internal friction angle $(\varphi)$ of the rock under certain conditions (wear flat roughness, dry sample) $[6,1,31,24,17,2,42]$. Dagrain [15] and Rostamsowlat [44] have also shown that reducing the wear flat roughness can lead to a reduction in the friction coefficient which in turn leads to an increase in the contact stress $(\sigma \simeq 3 q-5 q)$.

Finally, there is also evidence that the contact stress can be strongly affected by the angle of inclination $\beta$ (or the angle between the wear flat and the velocity vector) $[20,21,8,43]$. More recently, a numerical study by Zhou \& Detournay [51] suggests that the scaled contact stress $\left(\prod=\frac{\sigma}{q}\right)$ is predominantly controlled by one dimensionless number $\eta \simeq \frac{E^{*} \tan \beta}{q}$ (where $E^{*}=\frac{E}{1-\nu^{2}}, E$ is the elastic modulus and $\nu$ is the Poisson's ratio). With some similarities with the response of a blunt indenter $[51,5,26,13,28,27]$, the number $\eta$ is shown to control the frictional contact regime either elastic, elasto-plastic or plastic, see Fig. 6. 


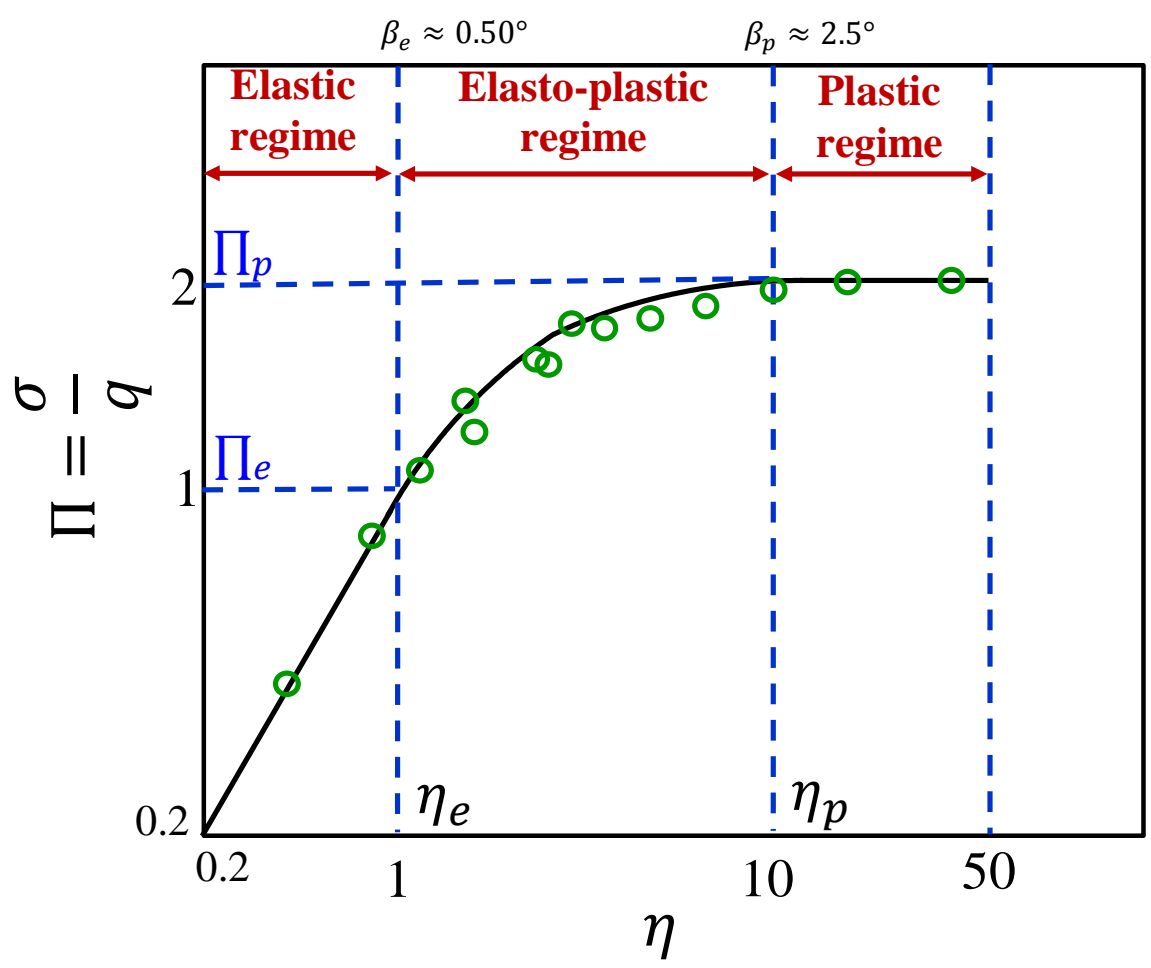

Fig. 6: Expected schematic of three regimes of frictional contact. Subscripts $e$ and $p$ stand for elastic and plastic regimes, respectively. Green circles are the results of numerical simulation by Zhou \& Detournay [51].

The numerical work by Zhou \& Detournay [51] was based on some assumptions: $(i)$ the friction angle of the wear flat $(\phi)$ is considered to be equal to internal friction angle of the rock $(\varphi),(i i)$ the rock is assumed to be an elasto-perfectly plastic material with a Mohr-Coulomb yield function deforming under plane stain condition, and (iii) the contact process is independent of the cutting process taking place ahead of the cutter.

\section{Experimental setup}

\subsection{Scratching device (Wombat)}

The "Wombat" machine developed by EPSLOG Engineering SA and housed in the Rock Mechanics Testing Laboratory of CSIRO (Perth, Australia) was used to scratch rocks by tracing a groove on the rock surface under controlled depth of cut and a predetermined constant horizontal velocity $\left(\boldsymbol{v}=4 \frac{\mathrm{mm}}{\mathrm{s}}\right)$ along the entire cut (see Fig. 7). The load-cell measured the three total force 
components $\left(F_{n}, F_{s}\right.$ and $\left.F_{t}\right)$ with a precision of less than $1 \mathrm{~N}$ over a full range of 0 to $\pm 3500 \mathrm{~N}$ (for more details see Refs. $[39,42,43]$ ).

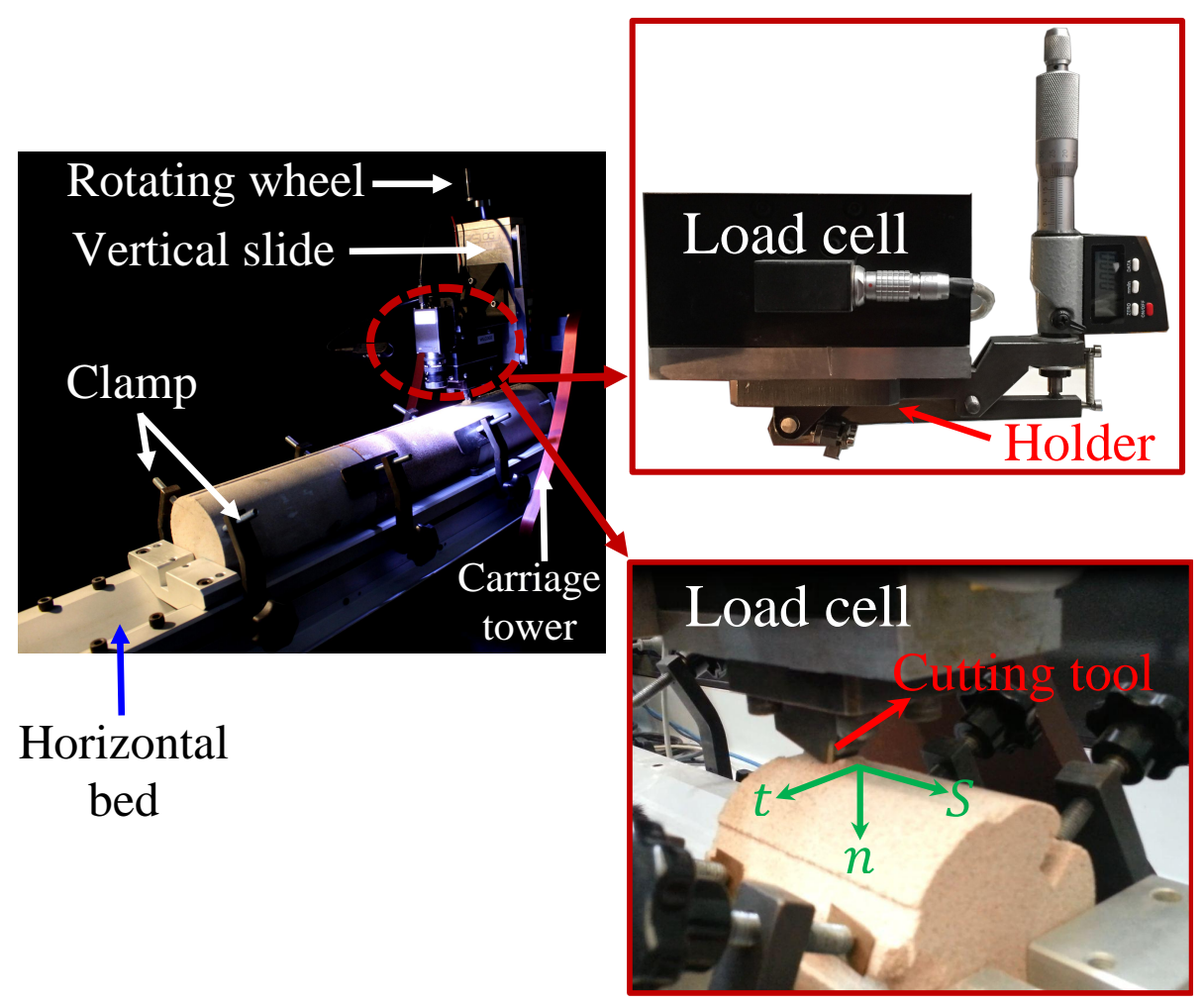

Fig. 7: The rock cutting machine (Wombat, Epslog SA).

\subsection{Cutter holder}

In order to vary the cutter back rake angle $\theta$ (and thus the inclination angle $\beta$ ) in steps of $0.10^{\circ}$, a novel cutter holder was designed and manufactured. As shown in Fig. 8, this new holder consists of five main mechanical parts: $(i)$ a forked angle cutter holder body (fixed body), (ii) an adjustable arm, (iii) an extension spring, $(i v)$ a digital micrometer, and $(v)$ a cutter seat.

The holder mounts on the base of the load-cell. The adjustable arm is attached to the fixed body with two high tensile screws to lock the adjustable arm in place. One extension spring maintains contact between the micrometer spindle face and the adjustable arm (bump) as the rake angle is being varied. By loosening the high tensile screws, the adjustable arm can be rotated a few degrees to a maximum of approximately $6.5^{\circ}$. Additional cutter seats were 
designed with different inclinations of the back surface offering a broader range of back rake angles $(\theta)$, and thus inclination angle $(\beta)$, see Fig. 8 .

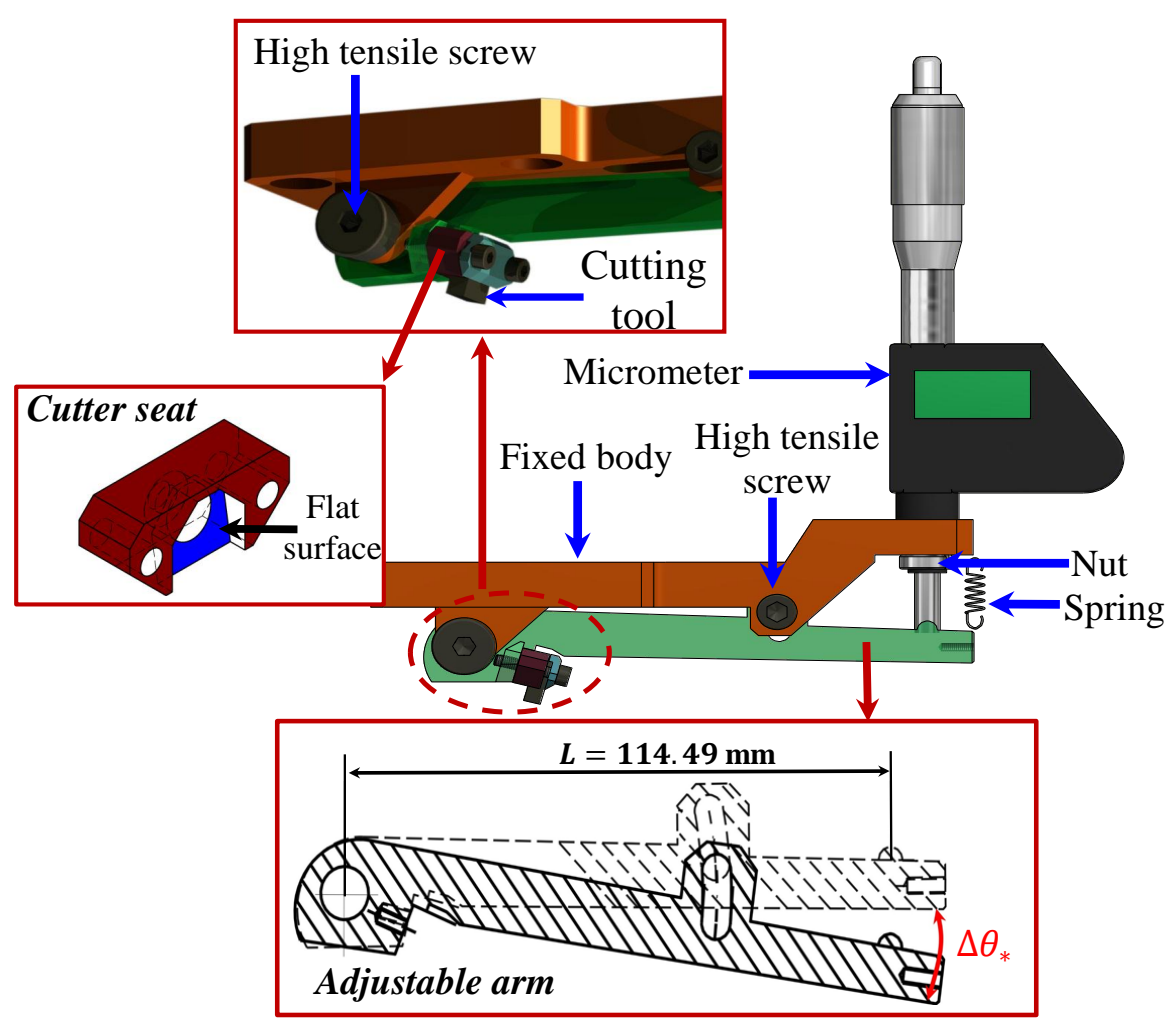

Fig. 8: Schematic of the new cutter holder with fine adjustable inclination angle.

The chamfer angle $\chi$ (a constant value for a given blunt cutter) is the angle between the wear flat surface and the normal to the cutting face (or in other words, the angle between the wear flat surface and the velocity vector when the back rake angle is set to zero $\theta=0^{\circ}$ ), see Fig. 9a. As the blunt cutter is mounted on the cutter seat with a forward inclination (back rake angle $\theta$ ), the wear flat inclination angle $(\beta)$ with respect to the direction of cutter motion (velocity vector $\boldsymbol{v}$ ) is given by (Fig. 9b):

$$
\beta=\chi-\theta
$$




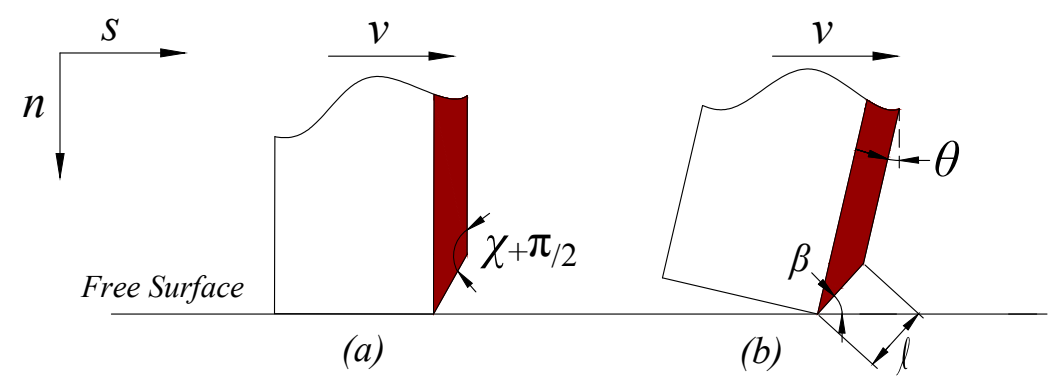

Fig. 9: Definition of $(a)$ the chamfer angle $\chi$, and $(b)$ the inclination angle $\beta$ between the wear flat surface of a blunt PDC cutter and the velocity vector $(v)$.

The back rake angle of the cutter is first set to an initial back rake angle $\left(\theta_{*}\right)$ and then incrementally increased in steps of $\Delta \theta_{*}$ to reach to the desired value of back rake angle $(\theta)$ :

$$
\theta=\theta_{*}+\Delta \theta_{*}
$$

Combining Eq. 7 and Eq. 8, the inclination angle $(\beta)$ is calculated using the following relation:

$$
\beta=\chi-\theta_{*}-\Delta \theta_{*}
$$

where

$$
\Delta \theta_{*}=\arcsin \left(\frac{\Delta z}{L}\right)
$$

and $\Delta z$ and $L$ are the desired relative displacement of the spindle and the radius of rotation ( $L=114.49 \mathrm{~mm}$ ), respectively (see Fig .8).

Once a blunt cutter has been placed on the machine, the initial back rake angle $\left(\theta_{*}\right)$ must be measured when $\Delta \theta_{*}=0^{\circ}$. For this purpose, knowledge of the exact orientation of the velocity vector $(\boldsymbol{v})$ is necessary to measure the effective back rake angle and eventually the inclination angle. The challenge in measuring the initial back rake angle $\left(\theta_{*}\right)$ is that the velocity vector is not necessarily parallel with the $s$-axis (or base of the load sensor). The best approach to find the velocity direction is via a graphical method using photographic images of a blunt cutter mounted on the machine at different positions along the motion of the cutter.

Once the Wombat machine was leveled with a dual axis $(X$ and $Y)$ mini digital protractor (with a precision of $\pm 0.08^{\circ}$ ), the tripod and the camera (Canon EOS 400D) were also leveled with a bubble level (attached to the pods) and the camera internal gyroscope, respectively. A macro lens (Canon EF $100 \mathrm{~mm} \frac{f}{2.8}$ USM) was also used to take high resolution close-up photographs of the cutter.

To construct the velocity vector $\boldsymbol{v}$ (or the reference line), several pictures of the cutter were taken in burst mode while the cutter moved forward, as 
depicted in Fig. 10a. All photos were then merged into one image, on which we define $P_{1}$ as a specific point on the cutter (cutter tip for example) and track the position of the same point (cutter tip) as $P_{2}, P_{3}$ and $P_{4}$ on images of the cutter at successive locations along the stroke (Fig. 10a). The velocity vector was then simply drawn by passing a line through all of the points, see Fig. 10b.

Another photo was then taken from the cutter (Fig. 11a) whose edges can be highlighted with an edge detection algorithm, see Fig. 11b. The picture was then merged with the previous picture containing the velocity vector, see Fig. 12. The angle between the cutting face and the velocity vector $\left(\frac{\Pi}{2}-\theta_{*}\right)$ was finally measured.

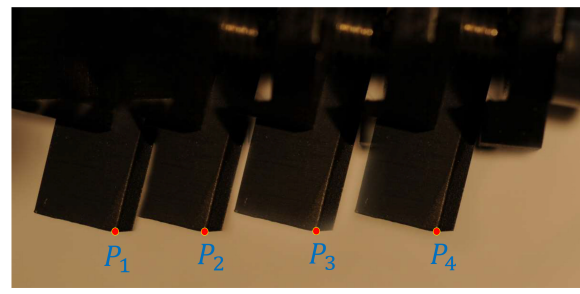

(a)

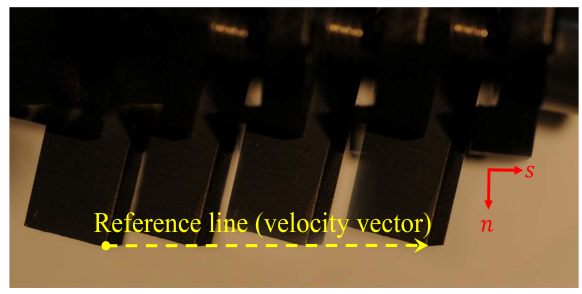

(b)

Fig. 10: $(a)$ Merged pictures of a cutter at successive positions, and $(b)$ geometrical estimate of the direction of the velocity vector.

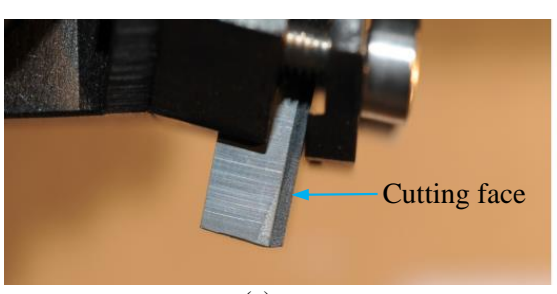

(a)

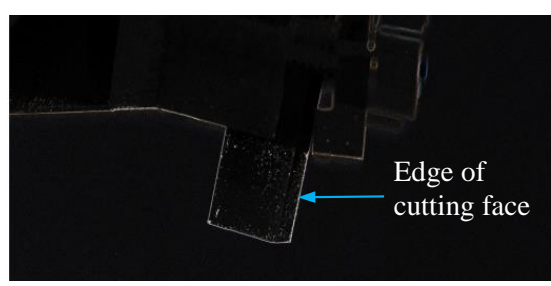

(b)

Fig. 11: (a) Photo of a blunt cutter, and (b) blunt cutter edges (ImageJ software). 


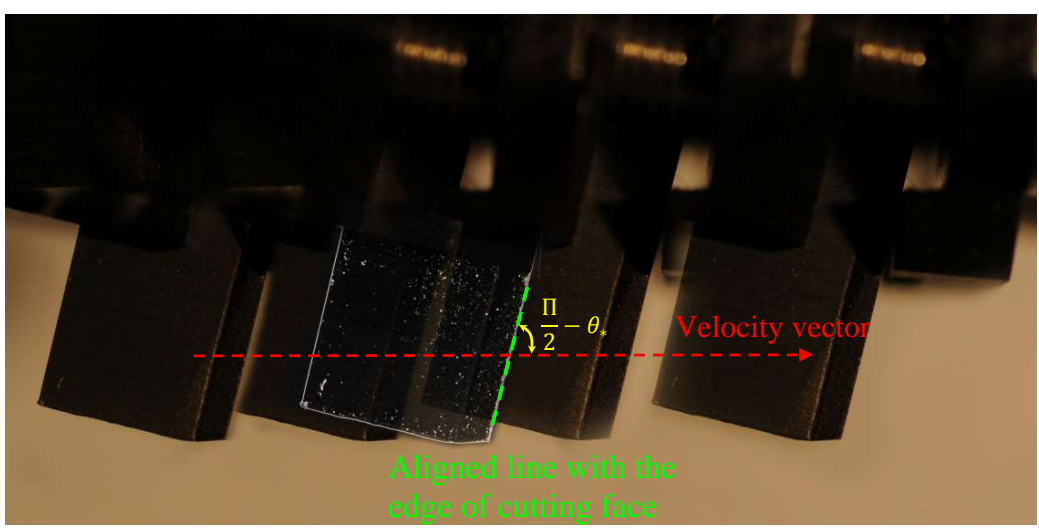

Fig. 12: Merged picture showing the direction of the velocity vector and the cutting face edge.

To validate the method, a cutter seat was selected and various displacements (ranging from $0.199 \mathrm{~mm}$ to $1.998 \mathrm{~mm}$ ) were applied to the micrometer corresponding to different values of back rake angles $\left(\Delta \theta_{*}\right.$ set). The angle was measured four times using the graphical method outlined earlier ( $\Delta \theta_{*}$ measured). Table 1 shows the consistent match between the measured and the set values of the back rake increments.

Table 1: Comparison between back rake angle increment set with the micrometer and measured via the image processing procedure.

\begin{tabular}{ccc|}
\hline Micrometer displacement $\Delta z(\mathbf{m m})$ & $\Delta \theta_{*}$ set & $\Delta \theta_{*}$ measured \\
\hline \hline 0.199 & $0.10^{\circ}$ & $0.12^{\circ}$ \\
0.399 & $0.20^{\circ}$ & $0.18^{\circ}$ \\
0.599 & $0.30^{\circ}$ & $0.35^{\circ}$ \\
0.799 & $0.40^{\circ}$ & $0.43^{\circ}$ \\
0.999 & $0.50^{\circ}$ & $0.48^{\circ}$ \\
1.198 & $0.60^{\circ}$ & $0.64^{\circ}$ \\
1.398 & $0.70^{\circ}$ & $0.70^{\circ}$ \\
1.598 & $0.80^{\circ}$ & $0.77^{\circ}$ \\
1.798 & $0.90^{\circ}$ & $0.93^{\circ}$ \\
1.998 & $1.00^{\circ}$ & $1.10^{\circ}$ \\
\hline
\end{tabular}

\subsection{Cutters}

Two rectangular shaped PDC cutters (one sharp and one blunt) were used in this research with a width of $10 \mathrm{~mm}(\omega=10 \mathrm{~mm})$. Note that the wear flat surface of the blunt cutter was precisely machined by grinding an originally sharp cutter. 
The geometrical properties of a rectangular blunt cutter, the length of wear flat surface $(\ell)$ and the chamfer angle $(\chi)$, as schematically shown in Fig. 9, were measured precisely on a profile projector. The blunt cutter was photographed using a high resolution optical microscope (model AxioScope Imager A1). The procedure for measuring the geometrical dimensions of the cutters is detailed in Ref. [43]. The geometrical details of both the sharp and blunt cutters used for the cutting tests are summarized in Table 2.

Table 2: Geometrical specifications of the cutters used for testing.

\begin{tabular}{c|cc|}
\hline Cutter geometry & Sharp cutter & Blunt cutter \\
\hline \hline Width $(\mathrm{mm})$ & 10 & 10 \\
Wear flat length $(\mathrm{mm})$ & 0 & 1 \\
Wear flat area $\left(\mathrm{mm}^{2}\right)$ & 0 & 10 \\
Chamfer angle & $0^{\circ}$ & $18.44^{\circ}$ \\
\hline
\end{tabular}

\subsection{Rock materials}

One limestone (Tuffeau) and one sandstone (Mountain Gold) sample were used in the present study, and were selected based on their homogeneity and isotropic behavior in relation to rock cutting (meaning the cutting response is not affected by the direction in which the cut is carried out). The mechanical and physical properties of these two rock samples are listed in Table 3. The work was then extended to an additional eleven rock samples whose properties are listed in Appendix A. The methods used to determine the physical properties of the rock samples are illustrated in Appendix B.

Table 3: Physical properties of rocks used for cutting tests [43].

\begin{tabular}{|c|c|c|c|}
\hline Rock name & & Tuffeau & Mountain Gold \\
\hline "Compressive strength (MPa) & & 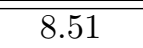 & $\overline{\overline{34}}$ \\
\hline Elastic modulus (GPa) & & 1.70 & 8.10 \\
\hline Poisson's ratio & & 0.24 & 0.20 \\
\hline Dry Porosity (\%) & & 41.49 & 15.70 \\
\hline Dry density $\left(\mathrm{Kg} / \mathrm{m}^{3}\right)$ & & 1360 & 1970 \\
\hline Permeability (mD) & & 39.07 & 2.09 \\
\hline$\underline{E^{*}}$ & & 211.97 & 248.16 \\
\hline \multirow{3}{*}{ Grain size distribution diameters } & $D_{10}(\mu m)$ & 24 & 8 \\
\hline & $D_{50}(\mu m)$ & 181 & 401 \\
\hline & $D_{90}(\mu m)$ & 533 & 792 \\
\hline
\end{tabular}




\section{Results and discussion}

Tests with a sharp cutter were first carried out to characterize the force associated with the pure cutting process as a function of the back rake angle based on Eq. 6. Those results were then used to estimate the force mobilized on the wear flat from the total force recorded during tests carried out with a blunt cutter at similar back rake angle; and eventually the contact stress $(\sigma)$ and the friction coefficient $(\mu)$ mobilized across the wear flat. The inclination angle $(\beta)$ of the blunt cutter was varied over a wide range of $-4.26^{\circ}$ to $14.90^{\circ}$. It was also decided to run the tests at a depth of cut of $0.70 \mathrm{~mm}(\mathrm{~d}=0.70 \mathrm{~mm})$ or in other words, in phase II for which it is assumed that the effective contact area has reached its limit value $\left(A_{f}=A_{f *}\right)$.

4.1 Influence of the wear flat inclination angle $(\beta)$ on the normal contact stress $(\sigma)$ and friction coefficient $(\mu)$

A campaign of cutting tests was carried out on samples of Tuffeau limestone and Mountain Gold sandstone. Fig. 13 \& Fig. 14 show the scaled contact stress $\left(\Pi=\frac{\sigma}{q}\right)$ and friction coefficient $(\mu)$ as a function of the inclination angle $(\beta)$. While the contact stress is affected by the inclination angle, the friction coefficient is relatively insensitive to the inclination angle. Estimate of the friction coefficient at negative angles is probably unreliable as the estimate of the tangential component of the contact force is very small and comparable to the level of precision of the system.

As can be seen in Fig. 13, it is remarkable that the contact stress is strictly positive for negative values of the inclination angle $\left(\beta<0^{\circ}\right)$, for which the wear flat (in theory) is not in contact with the rock. One possible explanation is that contact occurs between the rock and the relief surface of the cutter, possibly more pronounced in the case of the sandstone due to the coarse, angular nature of the material. 


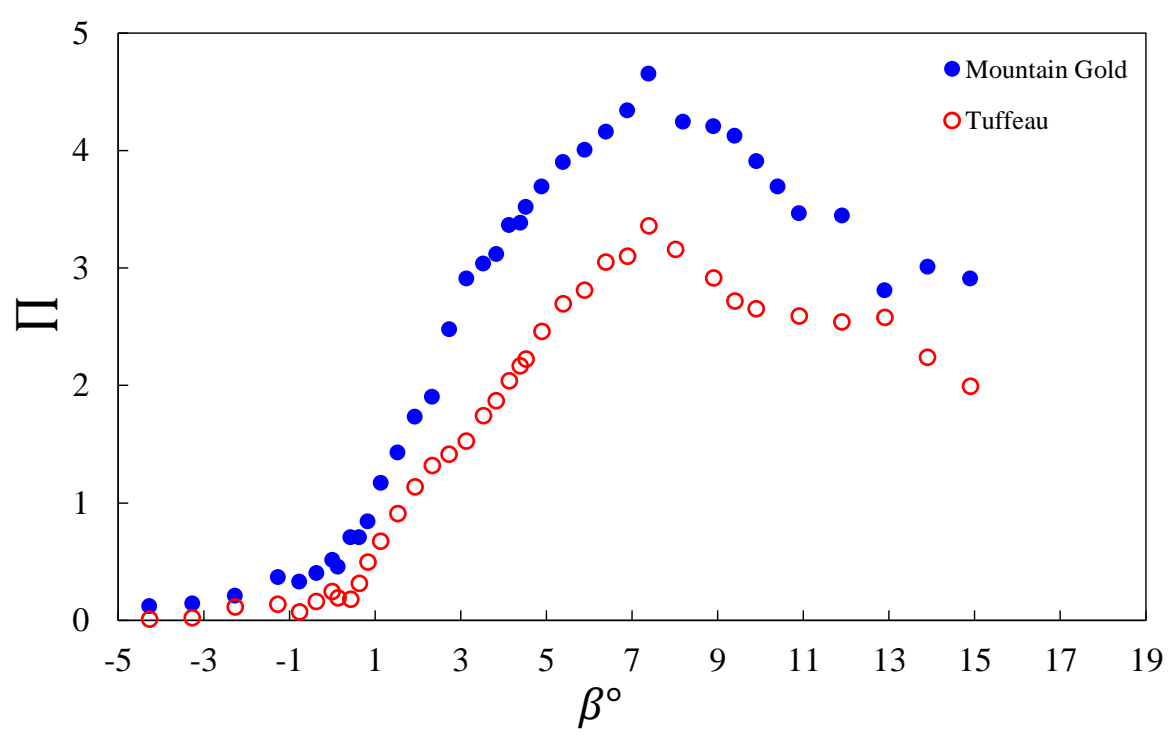

Fig. 13: Scaled contact stress versus inclination angle at $d=0.70 \mathrm{~mm}$. Tests conducted on Tuffeau limestone and Mountain Gold sandstone.

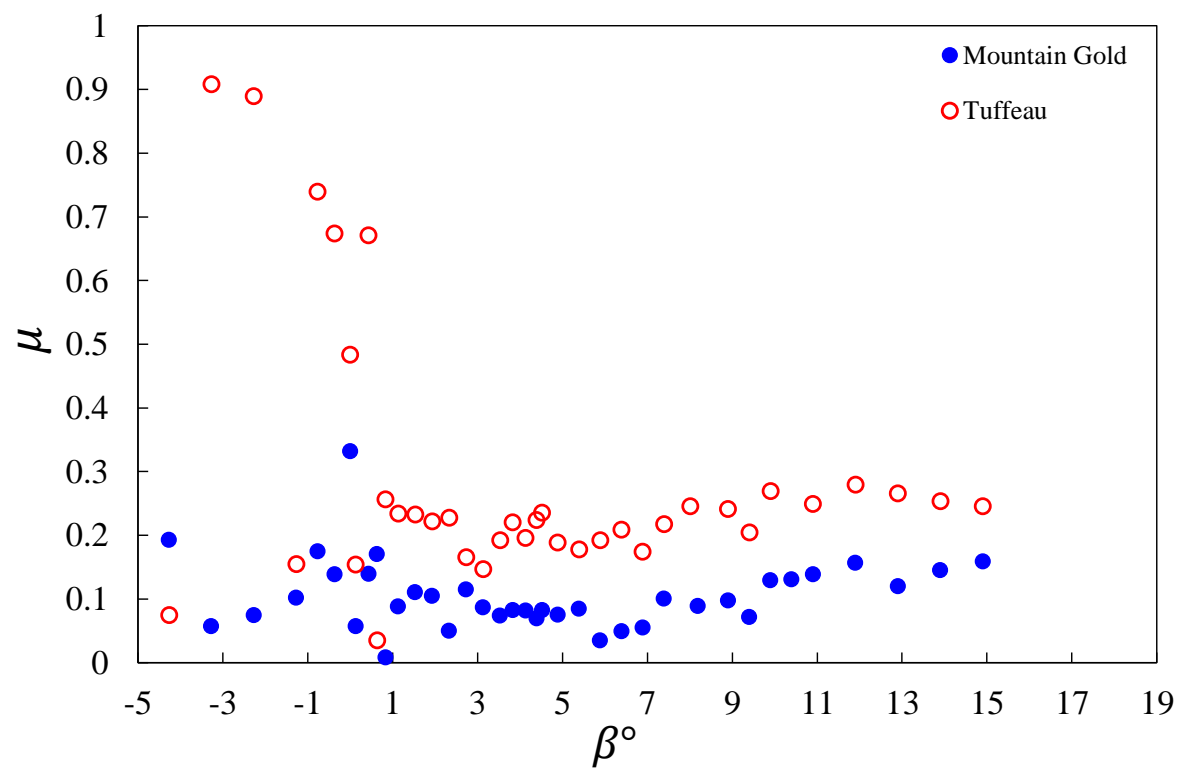

Fig. 14: Friction coefficient versus inclination angle at $\mathrm{d}=0.70 \mathrm{~mm}$. Tests conducted on Tuffeau limestone and Mountain Gold sandstone. 
Fig. $15 \&$ Fig. 16 show the cutting responses of the sharp and blunt cutters for the same back rake angle of $21.70^{\circ}$ such that the inclination angle $(\beta)$ is negative and equal to $-3.26^{\circ}$ while in the case of the sharp cutter, the angle (angle between the velocity vector and the relief surface) is $-21.70^{\circ}$, see Fig. 17. As shown in these figures, while the difference in the tangential component of the force is negligible there is a clear difference in the normal component supporting the idea that contact is taking place along the relief surface below a critical value of the relief angle $(\alpha)$.

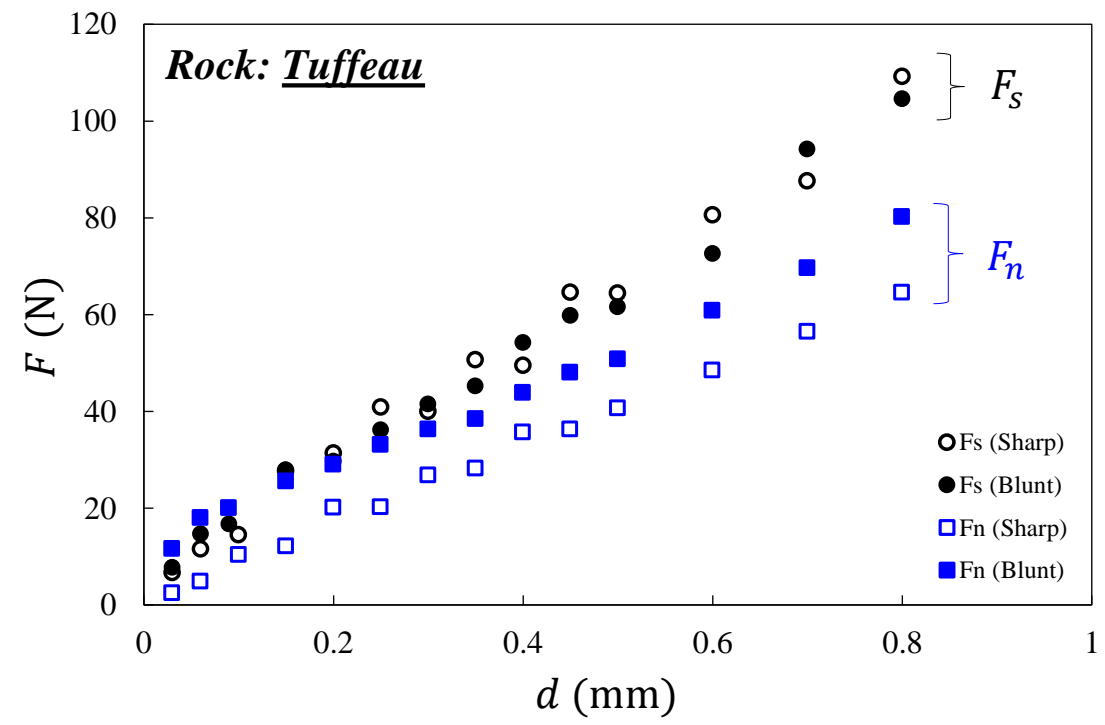

Fig. 15: Results of cutting tests carried out with a sharp cutter and a blunt cutter at $\theta=21.70^{\circ}$ on Tuffeau limestone. 


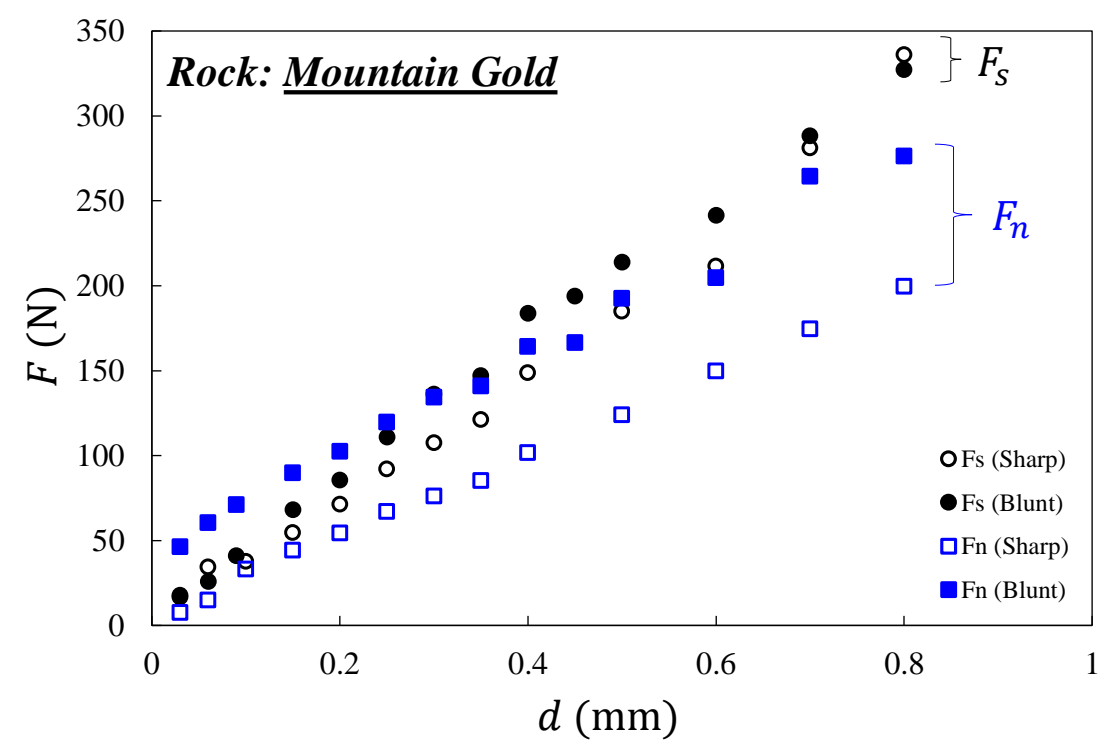

Fig. 16: Results of cutting tests carried out with a sharp cutter and a blunt cutter at $\theta=21.70^{\circ}$ on Mountain Gold sandstone.
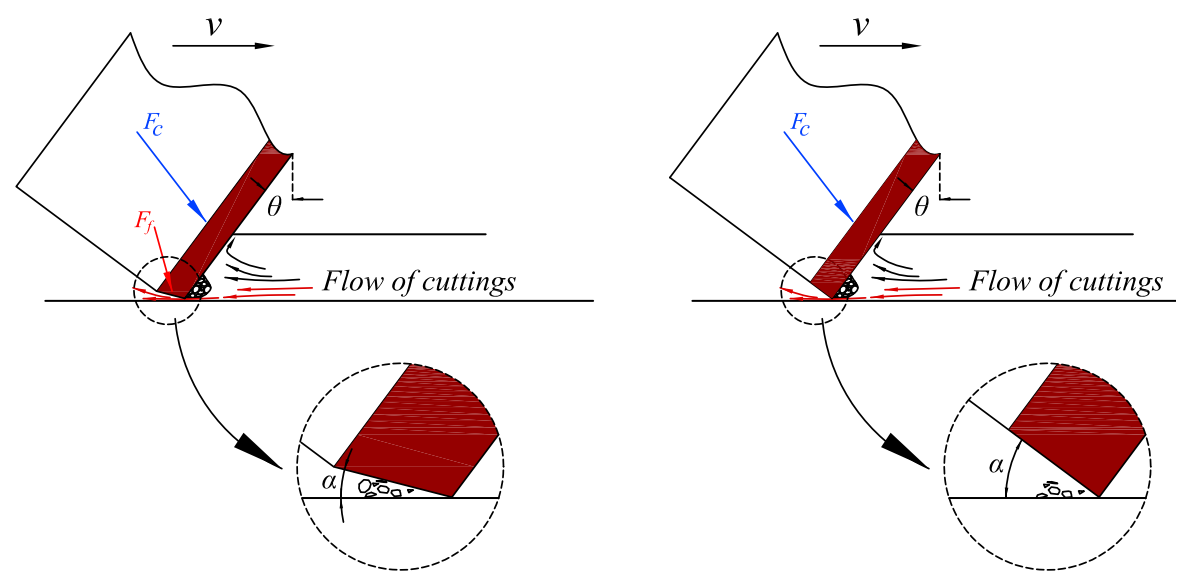

Fig. 17: Schematic of flow of the cuttings (or crushed materials) at negative inclination angle $\left(\beta<0^{\circ}\right)$. 
4.2 Three regimes of frictional contact

In an attempt to compare more closely the experimental results with the numerical simulation, we aim at identifying the three contact regimes predicted by the simulation: elastic, elasto-plastic and plastic. With no direct method to measure the nature of the deformation undergone by the rock material below the wear flat surface, we rely solely on the response in the diagram of scaled contact stress $\prod$ (for $\mathrm{d}=0.70 \mathrm{~mm}$ ) as a function of the number $\eta=\frac{E \tan \beta}{\left(1-\nu^{2}\right) q}$; see Fig. 18 for both Tuffeau limestone and Mountain Gold sandstone. The limit of the first regime was identified by the onset of deviation from a linear relation in the space ( $\prod$ vs $\eta$ ). The results suggest that the limit of the elastic regime $\left(\eta_{e}\right)$ is very similar for the two rock samples and occurs at about $\prod_{e} \simeq 1-2$, the elastic limit $\left(\eta_{e}\right)$ occurs at $\eta_{e} \simeq 10$ or similarly $\beta_{e} \simeq 2.5^{\circ}-3^{\circ}\left(\eta_{e} \simeq 8.66\right.$ and 10.23 for Tuffeau and Mountain Gold, respectively). Although, the overall trend is similar to the results of numerical simulations, see Fig. 6, there are also some noticeable differences.

Foremost, the apparent stiffness (or slope $(\lambda)$ in the elastic regime) is found much smaller than the value predicted by the numerical simulation $(\lambda=1)$ [51]. There is no clear explanation for this observation at this time, we can only mention that numerical simulation does not account for the cutting process taking place ahead of the cutter. Numerical simulation relies on the hypothesis that the two processes (cutting and frictional processes) are fully independent. There are suggestions that some of the crushed materials resulting from the cutting process could be forced between the wear surface and the virgin rock. One could then argue that some of the cuttings and crushing taking place at the tip of the cutter may lead to micro-fracturing in the material below the cutter tip leading to an apparent decrease of the material stiffness. Furthermore, even during the tests carried out with a blunt cutter at very shallow depth of cut $(d<0.10 \mathrm{~mm})$ and small inclination $\left(\beta \simeq 1^{\circ}\right)$, cutting takes place with removal of particles of rock at the cutter tip [43].

The onset of the plastic regime is located at about $\eta_{p} \simeq 30$ which compares well with the results of numerical simulation [51], the limit scaled stress $\left(\prod_{p}\right)$ is found equal to about 3.2 and 4.5 for Tuffeau and Mountain Gold, respectively, against about 2 for numerical simulation. However, numerical simulation assumes a friction coefficient at the interface quite high $(\mu=0.557)$ while experimental results indicate a much lower value (for this particular cutter $[43,44]$ ), as presented in Fig. 18. The friction coefficients (and therefore the friction angles) derived from tests carried out with the blunt cutter are found much smaller than the internal friction coefficient of the two rock materials $\left(\varphi=26.20^{\circ}\right.$ and $32.40^{\circ}$ for Tuffeau and Mountain Gold, respectively), as presented in Appendix B. This is most probably caused by the relatively smooth-polished nature of the wear flat of the blunt cutter leading to relatively small friction and relatively high contact stress $(\sigma \simeq 3-4 q)[43,44]$. This observation is consistent with results of Dagrain [15] and Rostamsowlat [44] who showed that increase of the friction coefficient at the wear flat in- 
terface is accompanied by a decrease of the contact stress. Table $4 \&$ Table 5 summarize the results of both the elastic and plastic contact regimes.

Table 4: Estimate of the properties of the elastic regime for results of cutting tests conducted on Tuffeau and Mountain Gold at $\mathrm{d}=0.70 \mathrm{~mm}$.

\begin{tabular}{c|ccccc}
\hline Rock & $\beta_{e}$ & $\eta_{e}$ & $\prod_{e}$ & $\lambda$ & $\mu_{e}$ \\
\hline \hline Tuffeau & $2.34^{\circ}$ & 8.66 & 1.34 & 0.15 & 0.23 \\
Mountain Gold & $2.50^{\circ}$ & 10.83 & 1.93 & 0.18 & 0.10 \\
\hline
\end{tabular}

Table 5: Estimate of the properties of the plastic regime for results of cutting tests conducted on Tuffeau and Mountain Gold at $\mathrm{d}=0.70 \mathrm{~mm}$.

\begin{tabular}{|c|c|c|c|c|}
\hline Rock & $\beta_{p}$ & $\eta_{p}$ & $\prod_{p}$ & $\mu_{p}$ \\
\hline Tuffeau & $7.40^{\circ}$ & 28.55 & 3.35 & 0.29 \\
\hline Mountain Gold & $7.40^{\circ}$ & 32.22 & 4.65 & 0.14 \\
\hline
\end{tabular}




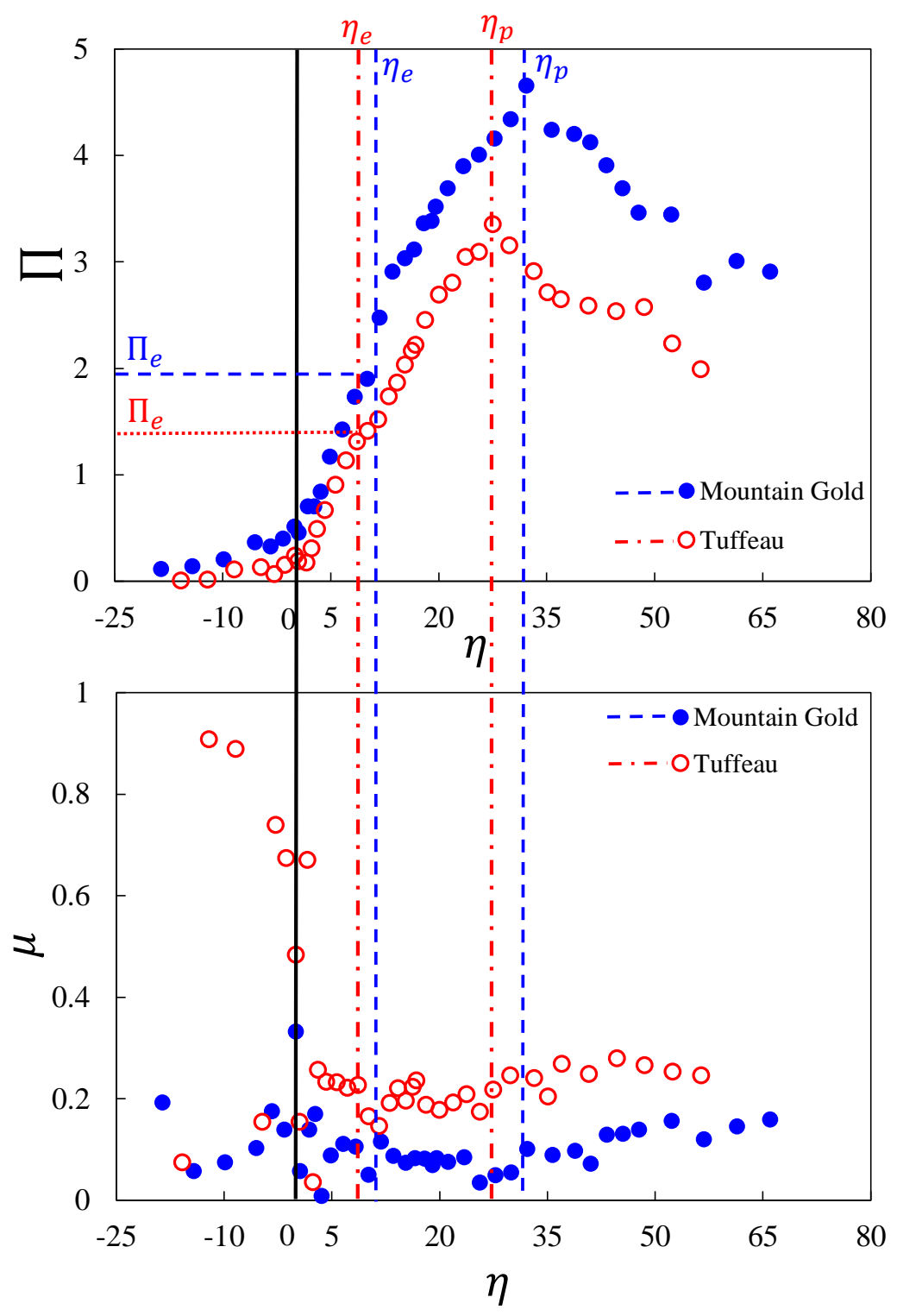

Fig. 18: Plot of the scaled contact stress $(\Pi)$ and friction coefficient $(\mu)$ as a function of the dimensionless number $\eta$ at $\mathrm{d}=0.70 \mathrm{~mm}$.

Finally, the extent of the plastic regime is observed to be quite short in the experimental results due to a decrease of the contact stress with the inclination angle (past $\beta \simeq 7^{\circ}-8^{\circ}$ ). The observed decrease in the estimate scaled contact stress could be attributed to the fact that the process associated with the wear 
flat surface transitions from a contained failure mechanism (contact problem) to an uncontained failure process (cutting problem). This explanation is supported by results shown in Fig. 19, where the tests carried out on Tuffeau and Mountain Gold with a blunt cutter and a sharp cutter at a depth of cut small enough $(\mathrm{d}=0.09 \mathrm{~mm})$ so that only the wear flat surface is in contact with the rock (at large inclination angle $\beta>5.16^{\circ}$ ) in tests carried out with the blunt cutter. The results show that data pertaining to the tests carried with the blunt cutter with increasing angle $\beta$ are consistent with the results pertaining to the tests performed with a sharp cutter at a very large back rake angle $(\theta)$.

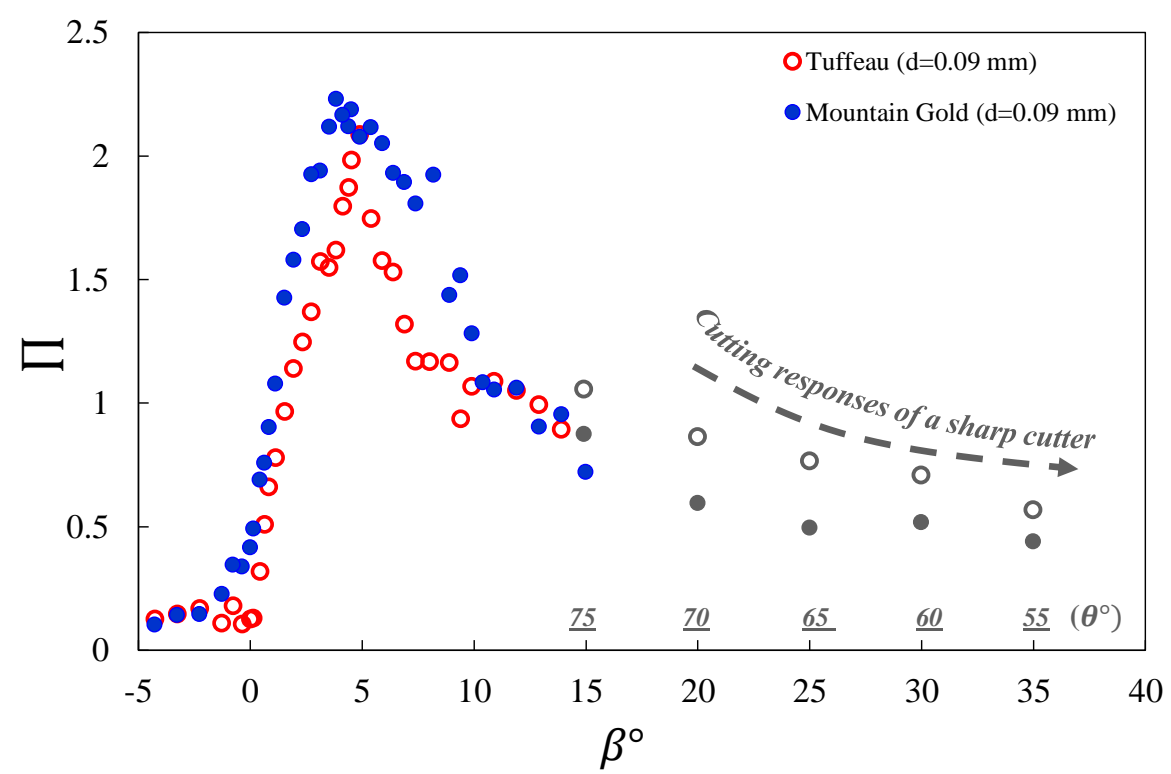

Fig. 19: Scaled contact stress as a function of the contact surface inclination $\beta$ for a blunt cutter (only wear flat in contact with the rock) and a sharp cutter (tests carried out at a very large back rake angle $\theta$ ).

\subsection{Generalization to other rock samples}

The results presented in the previous section were extended to a wider range of sedimentary rock samples (three limestones: Tuffeau, Indiana and Savonnieres; and ten sandstones: Castlegate, Mountain Gold, Bentheimer, Boise, Berea I, Berea II, Buff Berea, Berea Sister Gray, Berea Upper Gray, Carbon Tan) using the same blunt cutter as well as the same depth of cut $(\mathrm{d}=0.70 \mathrm{~mm})$, see Fig. 20 and Fig. 21. 


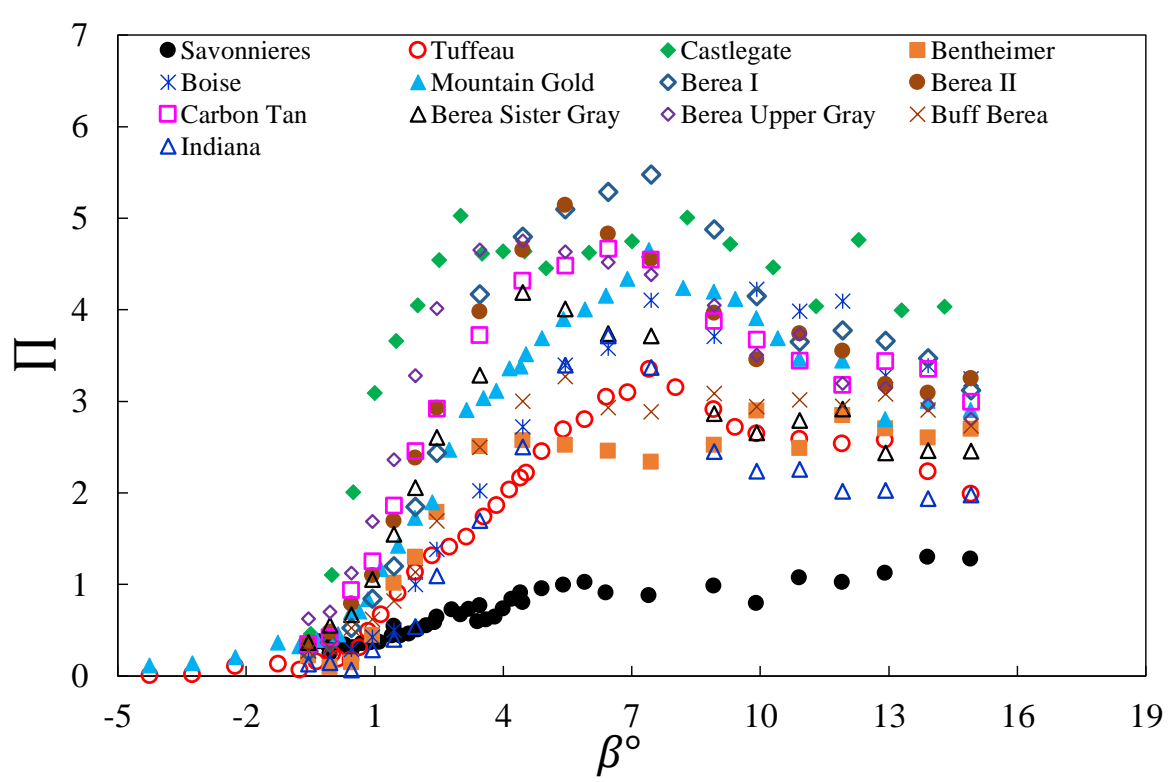

Fig. 20: Scaled contact stress $\left(\prod\right)$ versus inclination angle $(\beta)$. Tests performed at $\mathrm{d}=0.70 \mathrm{~mm}$.

The bounds of the elastic regime in terms of $\beta$ and $\eta\left(\beta_{e}\right.$ and $\left.\eta_{e}\right)$ are summarized in Table 6 along with the scaled contact stress at the elastic limit $\left(\prod_{e}\right)$, the slope in the elastic regime $(\lambda)$, the average friction coefficient in the elastic regime $\left(\mu_{e}\right)$, and the ratio $\frac{E^{*}}{q}$. 


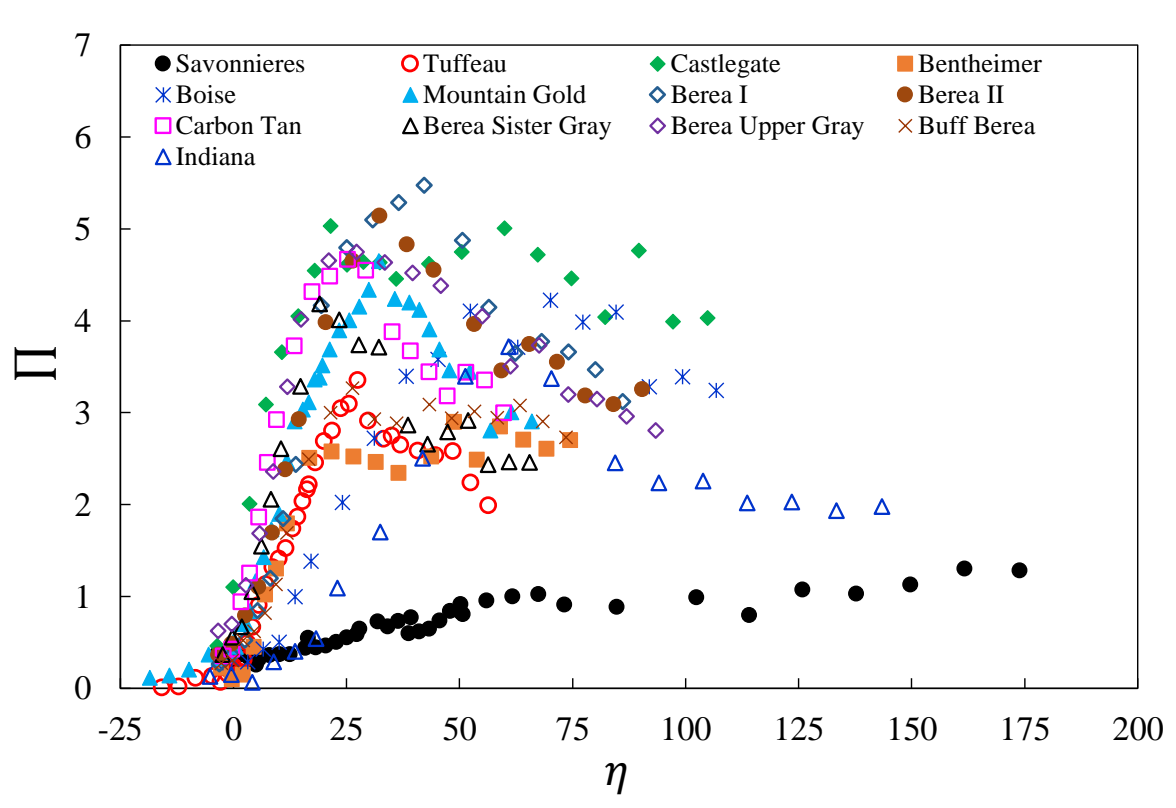

Fig. 21: Scaled contact stress (П) versus dimensionless number $\eta$. Tests performed at $d=0.70 \mathrm{~mm}$.

Consistent with results described earlier (section 4.2), the elastic limit is found at much larger inclination angle and therefore dimensionless number $\eta$ than in the numerical simulation. The slope $(\lambda)$ in the elastic regime is also smaller than the value derived from numerical simulation [51]; about $0.15-0.25$ against 1 (slope in the dimensionless space $\prod_{e}-\eta_{e}$ ). Interestingly, the elastic limit sits at about the same angle $\beta_{e} \simeq 2^{\circ}-3^{\circ}$ and consequently similar value of $\eta$ for some rock materials characterized by a similar ratio of $\frac{E^{*}}{q}$. 
Table 6: The bounds of elastic regime (from tests performed at $\mathrm{d}=0.70 \mathrm{~mm}$ ).

\begin{tabular}{c|cccccc}
\hline Rock & $\beta_{e}$ & $\eta_{e}$ & $\prod_{e}$ & $\lambda$ & $\mu_{e}$ & $\frac{E^{*}}{q}$ \\
\hline \hline Tuffeau & $2.34^{\circ}$ & 8.66 & 1.34 & 0.15 & 0.23 & 211.97 \\
Indiana & $3^{\circ}$ & 28.22 & 1.52 & 0.05 & 0.09 & 543.77 \\
Savonnieres & $3^{\circ}$ & 34.24 & 0.69 & 0.02 & 0.42 & 653.43 \\
\hline Castlegate & $1.50^{\circ}$ & 10.77 & 4.09 & 0.37 & 0.11 & 304.46 \\
Mountain Gold & $2.50^{\circ}$ & 10.83 & 1.93 & 0.18 & 0.10 & 248.16 \\
Bentheimer & $2.45^{\circ}$ & 11.97 & 1.79 & 0.14 & 0.02 & 279.85 \\
Boise & $3^{\circ}$ & 21.01 & 1.52 & 0.07 & 0.007 & 400.94 \\
Berea I & $2.45^{\circ}$ & 13.82 & 2.85 & 0.20 & 0.06 & 323.14 \\
Berea II & $2.45^{\circ}$ & 14.53 & 2.90 & 0.19 & 0.07 & 339.66 \\
Buff Berea & $2.45^{\circ}$ & 11.82 & 1.84 & 0.15 & 0.04 & 276.88 \\
Berea Sister Gray & $2.45^{\circ}$ & 10.52 & 2.60 & 0.24 & 0.04 & 245.94 \\
Berea Upper Gray & $2.50^{\circ}$ & 15.31 & 3.91 & 0.25 & 0.02 & 350.76 \\
Carbon Tan & $2.50^{\circ}$ & 9.26 & 3.11 & 0.33 & 0.03 & 212.12 \\
\hline
\end{tabular}

Table 7 shows values describing the plastic regime in terms of its bound $\left(\eta_{p}\right)$, scaled contact stress $\left(\prod_{p}\right)$, and friction coefficient $\left(\mu_{p}\right)$. The onset of the plastic regime for most rocks takes place for $\eta_{p} \simeq 20-70$ consistent with the numerical simulation, while the magnitude of the scaled contact stress in the plastic regime varies between 1 and 6 . 
Table 7: Estimated value for the onset of the plastic regime (from tests performed at $\mathrm{d}=0.70 \mathrm{~mm})$.

\begin{tabular}{c|ccccc|}
\hline \multicolumn{1}{c}{ Rock } & $\beta_{p}$ & $\eta_{p}$ & $\prod_{p}$ & $\mu_{p}$ & $\frac{E^{*}}{q}$ \\
\hline \hline Tuffeau & $7.40^{\circ}$ & 28.55 & 3.35 & 0.29 & 211.97 \\
Indiana & $6.45^{\circ}$ & 60.87 & 3.71 & 0.07 & 543.77 \\
Savonnieres & $5.9^{\circ}$ & 67.52 & 1 & 0.42 & 653.43 \\
\hline Castlegate & $3^{\circ}$ & 21.56 & 5.02 & 0.21 & 304.46 \\
Mountain Gold & $7.40^{\circ}$ & 32.22 & 4.65 & 0.14 & 248.16 \\
Bentheimer & $4.45^{\circ}$ & 21.77 & 2.62 & 0.09 & 279.85 \\
Boise & $7.45^{\circ}$ & 52.42 & 4.20 & 0.07 & 400.94 \\
Berea I & $7.45^{\circ}$ & 42.25 & 5.47 & 0.09 & 323.14 \\
Berea II & $5.45^{\circ}$ & 32.40 & 5.13 & 0.06 & 339.66 \\
Buff Berea & $5.45^{\circ}$ & 26.41 & 3.26 & 0.06 & 276.88 \\
Berea Sister Gray & $4.45^{\circ}$ & 19.13 & 4.18 & 0.02 & 245.94 \\
Berea Upper Gray & $4.45^{\circ}$ & 27.29 & 4.75 & 0.03 & 350.76 \\
Carbon Tan & $6.45^{\circ}$ & 23.98 & 4.66 & 0.13 & 212.12 \\
\hline
\end{tabular}

For most rock materials, the friction coefficient in the plastic regime is quite small when compared to the internal friction angle of the rock most probably caused by the polished nature of the wear surface, see Fig. 22. Results are again consistent with the results by Dagrain [15] and Rostamsowlat [44] as relatively high contact stresses are observed for most materials $(\Pi \simeq 3-5)$ while friction coefficients are quite small (due to the polished nature of the wear flat surface of the blunt cutter). 


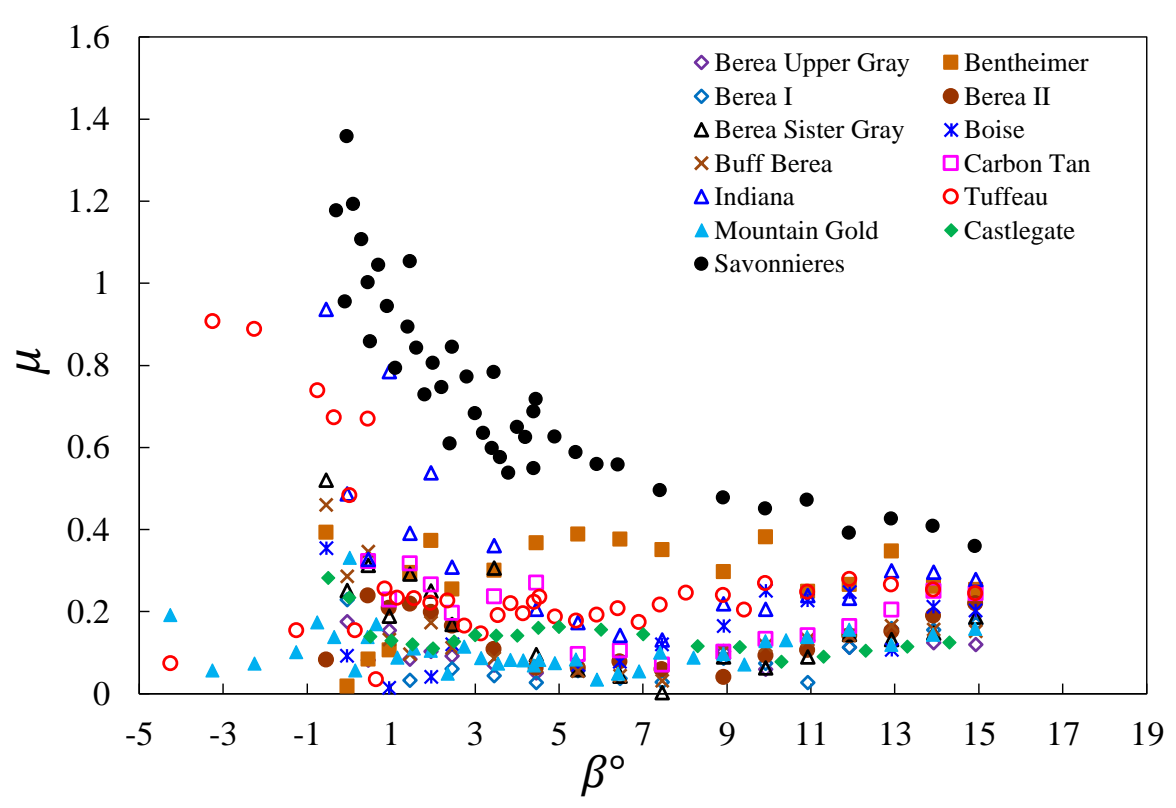

Fig. 22: Plot of friction coefficient $(\mu)$ as a function of inclination angle $(\beta)$ for thirteen rock samples at $\mathrm{d}=0.70 \mathrm{~mm}$.

Only in the case of Savonnieres sample, we observe a large friction coefficient associated with a lower contact stress $(\Pi \simeq 1)$. After tests had been carried out in samples of Savonnieres, the wear surface of the cutter was observed under a scanning electron microscope (SEM), and the results indicated the presence of a high amount of Silicon (a rock element) in the asperities of the wear flat which implies that rock powders adhere to the PDC wear flat yielding a high friction coefficient (rock against rock) and in turn lower contact stress.

\section{Conclusion}

The main goal of this work was to experimentally measure the effect of the inclination angle $(\beta)$ between the wear flat and the cutter velocity vector $(\boldsymbol{v})$ on the contact stress $(\sigma)$ and friction coefficient $(\mu)$ mobilized across the wear flat surface of a blunt cutter. An extensive and comprehensive set of cutting experiments was performed with a blunt cutter on thirteen different sedimentary quarry rock materials. One essential contribution of this work was the design of a novel cutter holder and a step by step experimental procedure to adjust precisely the angle $\beta$ with a precision of the order of $0.10^{\circ}$. This unique experimental setup means that cutting experiments under the same 
depth of cut $(d)$, cutting velocity $(\boldsymbol{v})$ but different inclination angles $(\beta)$ could be carried out.

The results confirm the existence of three distinct regimes of frictional contact and confirm a suggestion by Zhou \& Detournay [51] that the scaled contact stress $\left(\prod=\frac{\sigma}{q}\right)$ mobilized across the wear flat is predominantly controlled by the one dimensionless number $\eta=\frac{E^{*} \tan \beta}{q}$ (where $E^{*}=\frac{E}{1-\nu^{2}}$ ).

The results indicate that the elastic bound is located at about the same inclination angles of $\beta_{e} \simeq 2^{\circ}-3^{\circ}$ and eventually the same number $\eta_{e}$ for the rock materials with similar $\frac{E^{*}}{q}$. However, the slope in the elastic regime ranges from $0.15-0.25$ (in the dimensionless space $\prod-\eta$ ), while numerical simulation suggests a slope of about 1 . There is no clear explanation at this time for this observed difference.

Experimental results also show that the plastic bound $\left(\eta_{p}\right)$ varies in the range of 20 to 70 which is well in line with results of numerical simulation. The scaled contact stress within the plastic regime $\prod_{p}$ varies from 1 to 6 against about 2 in the numerical simulation. This can possibly be explained by the fact that most experiments were carried out with a blunt cutter characterized by a polished wear surface leading to relatively small friction coefficient and in turn higher contact stress, which is consistent with the results obtained by Dagrain [15] and Rostamsowlat [44]. Within the plastic regime, once the inclination angle of the wear flat surface passes a certain angle (varying from $5.50^{\circ}$ to $8^{\circ}$ ), the contact stress decreases with inclination angle, as the cutting response transits from a contained (contact process) to an uncontained failure process (cutting) as the angle increases.

This work demonstrates that any single cutter experiment carried out in the laboratory with a blunt cutter must carefully assess the value of the inclination angle between the wear flat and the velocity vector, as an error of only $1^{\circ}$ to $2^{\circ}$ can lead to significant differences in the magnitude of the force acting on the tool.

Further work is also necessary to understand some of discrepancy between experimental and numerical results. Additional tests with a blunt cutter characterized by a rough wear surface will help establish the effect of a higher friction coefficient on the response in the three identified regimes. Further work should also be devoted to the governing assumption that underpins the numerical work and the processing of experimental data, namely that the cutting response of a blunt tool can be decomposed into two independent processes.

Acknowledgements The first author would like to thank Joel Sarout and Jeremie Dautriat at CSIRO (Commonwealth Scientific and Industrial Research Organisation) for granting access to Rock Mechanics Testing laboratory, research facilities and rock samples. The authors would like to thank Emmanuel Detournay at the University of Minnesota for his valuable and fruitful discussions. A special thanks to Gregory Lupton and Stephen Banks at CSIRO for their assistance in the design of cutter holder and tailored data acquisition system, respectively. The work has been supported by the Deep Exploration Technologies Cooperative Research Centre whose activities are funded by the Australian Government's Cooperative Research Centre Programme. This is DET CRC Document 2017/1032. 
Appendices

A Physical and mechanical properties of rock samples used for cutting tests

Table 8: Physical properties of rock samples used in this study [43].

\begin{tabular}{|c|c|c|c|c|c|c|c|}
\hline $\begin{array}{l}\text { Rock } \\
\text { type }\end{array}$ & $\begin{array}{l}\text { Rock } \\
\text { name }\end{array}$ & $\begin{array}{c}q \\
(M P a)\end{array}$ & $\begin{array}{c}\Phi_{\text {Dry }} \\
(\%)\end{array}$ & $\begin{array}{c}\rho_{\text {Dry }} \\
\left(\mathrm{Kg} / \mathrm{m}^{3}\right)\end{array}$ & $\begin{array}{c}K \\
(m D)\end{array}$ & $\begin{array}{c}E \\
(G P a)\end{array}$ & $\nu$ \\
\hline : & Indiana & 30.20 & 16 & 2290 & 4 & 16.10 & 0.14 \\
\hline 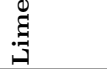 & Savonnieres & 19.58 & 26.50 & 1880 & 91.50 & 12.23 & 0.21 \\
\hline \multirow{11}{*}{ 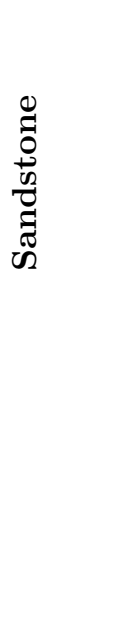 } & Castlegate & 15.03 & 26 & 1970 & 750 & 3.73 & 0.43 \\
\hline & Bentheimer & 49.13 & 24 & 2320 & 2300 & 12.82 & 0.26 \\
\hline & Boise & 23.73 & 28 & 1830 & 1700 & 8.60 & 0.31 \\
\hline & Berea I & 38.95 & 21 & 2090 & 496.39 & 11.80 & 0.25 \\
\hline & Berea II & 47.10 & 23 & 2320 & 260.51 & 13.04 & 0.43 \\
\hline & Buff Berea & 35.54 & 22 & 2008 & 150 & 9.32 & 0.23 \\
\hline & Berea & 50.40 & 21 & 2140 & 80 & 11.90 & 0.20 \\
\hline & (Sister Gray) & & & & & & \\
\hline & Berea & 44.80 & 19.46 & 2170 & 115 & 13.20 & 0.40 \\
\hline & (Upper Gray) & & & & & & \\
\hline & Carbon Tan & 56.2 & 15 & 2220 & 11 & 10.20 & 0.38 \\
\hline
\end{tabular}

$q$ : Uni-axial compressive strength, $\Phi_{D r y}$ : Dry porosity, $\rho_{D r y}$ : Dry density, $K$ : permeability, $E$ : Young's modulus, $\nu$ : Poisson's ratio 
Table 9: Standard deviation (SD) of porosity and permeability [43].

\begin{tabular}{|c|ccc|}
\hline \multicolumn{1}{c}{ Rock type } & Rock name & SD (Porosity) & SD (Permeability) \\
\hline \hline \multirow{3}{*}{ Limestone } & Tuffeau & 0.02 & 1.35 \\
& Indiana & 0.02 & 0.27 \\
& Savonnieres & 0.03 & 2.15 \\
\hline \multirow{5}{*}{ Sandstone } & Castlegate & 0.05 & 1.92 \\
& Mountain Gold & 0.02 & 0.12 \\
& Bentheimer & 0.07 & 2.18 \\
& Boise & 0.08 & 2.03 \\
& Berea I & 0.06 & 1.76 \\
& Berea II & 0.04 & 1.06 \\
& Buff Berea & 0.04 & 1.27 \\
& Berea Sister Gray & 0.03 & 1.08 \\
& Berea Upper Gray & 0.06 & 1.23 \\
& Carbon Tan & 0.06 & 0.20 \\
\hline
\end{tabular}


Table 10: Grain size distribution diameters and their standard deviations [43].

\begin{tabular}{|c|c|c|c|c|c|c|c|}
\hline $\begin{array}{l}\text { Rock } \\
\text { type }\end{array}$ & $\begin{array}{l}\text { Rock } \\
\text { name }\end{array}$ & $\begin{array}{l}D_{10} \\
(\mu m)\end{array}$ & $\begin{array}{l}\text { SD } \\
(\mu m)\end{array}$ & $\begin{array}{l}D_{50} \\
(\mu m)\end{array}$ & $\begin{array}{l}\text { SD } \\
(\mu m)\end{array}$ & $\begin{array}{l}D_{90} \\
(\mu m)\end{array}$ & $\begin{array}{l}\text { SD } \\
(\mu m)\end{array}$ \\
\hline \multirow{3}{*}{ 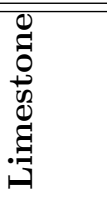 } & Tuffeau & 24 & 1.08 & 181 & 6.56 & 533 & 35.98 \\
\hline & Indiana & 9 & 1.25 & 515 & 56.46 & 1070 & 250.80 \\
\hline & Savonnieres & 3 & 2.16 & 95 & 8.23 & 466 & 18.92 \\
\hline \multirow{12}{*}{ 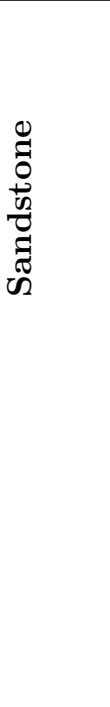 } & Castlegate & 8 & 1.95 & 13 & 2.92 & 345 & 16.32 \\
\hline & Mountain Gold & 8 & 2.65 & 401 & 3.75 & 792 & 22.35 \\
\hline & Bentheimer & 3 & 0.17 & 94 & 3.25 & 447 & 37.38 \\
\hline & Boise & 70 & 1.41 & 460 & 2.19 & 750 & 11.34 \\
\hline & Berea I & 93 & 3.04 & 197 & 4.03 & 346 & 21.64 \\
\hline & Berea II & 6 & 0.24 & 168 & 4.97 & 323 & 18.26 \\
\hline & Buff Berea & 8 & 0.41 & 214 & 4.02 & 380 & 21.49 \\
\hline & Berea & 27 & 1.43 & 162 & 2.58 & 313 & 20.82 \\
\hline & (Sister Gray) & & & & & & \\
\hline & Berea & 31 & 3.81 & 155 & 4.15 & 312 & 41.84 \\
\hline & (Upper Gray) & & & & & & \\
\hline & Carbon Tan & 102 & 1.58 & 186 & 3.04 & 325 & 20.77 \\
\hline
\end{tabular}

$D_{10}$ : is the diameter at which $10 \%$ of a sample's mass is comprised of smaller particles.

$D_{50}$ : is the diameter at which $50 \%$ of a sample's mass is comprised of smaller particles.

$D_{90}$ : is the diameter at which $90 \%$ of a sample's mass is comprised of smaller particles.

SD: stands for Standard Deviation.

\section{B Procedures to determine the physical and mechanical proprietors of rock samples}

A compression test machine (manufactured by Wykeham Farrance) was used to measure the uni-axial compressive strength $(q)$, Young's modulus $(E)$, Poisson's ratio $(\nu)$ and density $(\rho)$ of the rock samples used in this research. This machine is a displacement controlled machine which comprises of the main mechanical parts: a load frame, a load cell, two strain gauges for radial strain $\left(\epsilon_{r}\right)$ which have been manufactured by CSIRO, two compression platens, a control system, a gear box and two LVDTs (Linear variable displacement transducers) for axial strain $\left(\epsilon_{a}\right)$. The rock samples were cut into cylindrical shapes with length over diameter ratio of approximately 2.2 . The rock sample was set up in the compression test machine with transducers in place to measure sample axial and radial deformations and axial load. Each core plug was tested unsaturated. Each sample was axially loaded under a constant average axial strain rate $0.5 \%$ giving a loading rate of $0.259 \mathrm{~mm} / \mathrm{min}$ for both Bentheimer and Boise and $0.014 \mathrm{~mm} / \mathrm{min}$ for all other rocks until the samples failed. The Young's modulus $(E)$ and Poisson's ratio $(\nu)$ were determined from the tangential slope of the curve of deviatoric stress versus average axial strain and the tangential slope of the curve 
of average radial strain versus average axial strain between $40 \%$ and $60 \%$ of the maximum deviatoric stress, respectively.

To measure the grain (or particle) size of the rock samples, the rock samples were crushed very gently in a mortar with a plastic pestle. An Ultrasonic Bath Cleaner was also used to ensure the grains were completely separated from each other. A Mastersizer 3000 laser diffraction particle size analyzer was used to measure the grain (particle) sizes. This machine can be used for both wet and dry particles by measuring the intensity of the light scattered as a laser beam passes through a dispersed particulate sample. Fig. 23 shows the granular distribution of some rock samples used for cutting experiments.

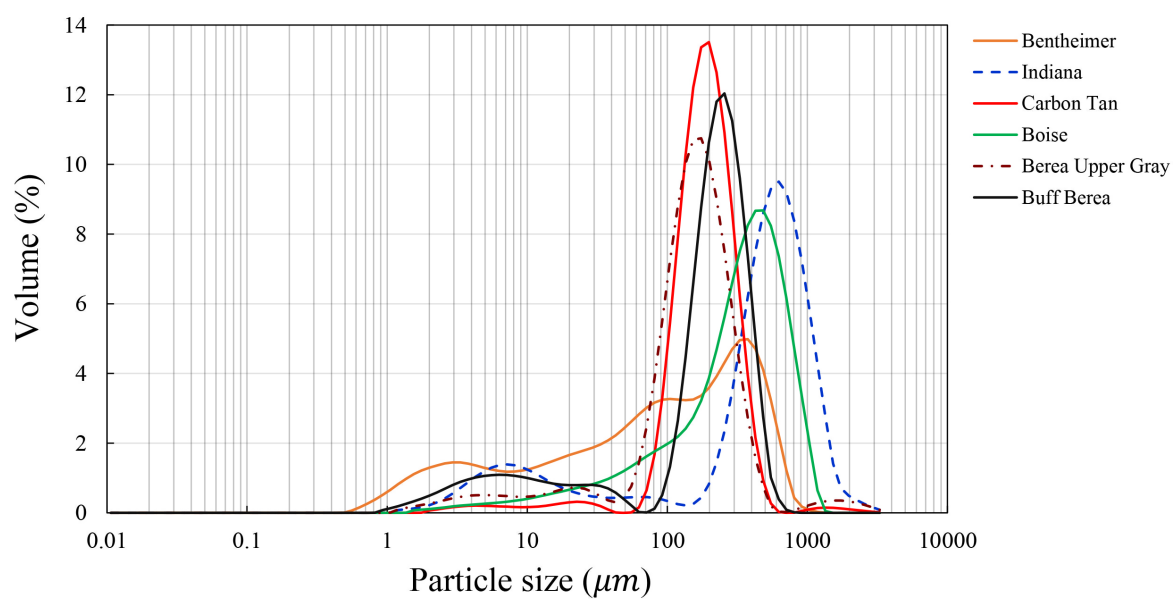

(a)

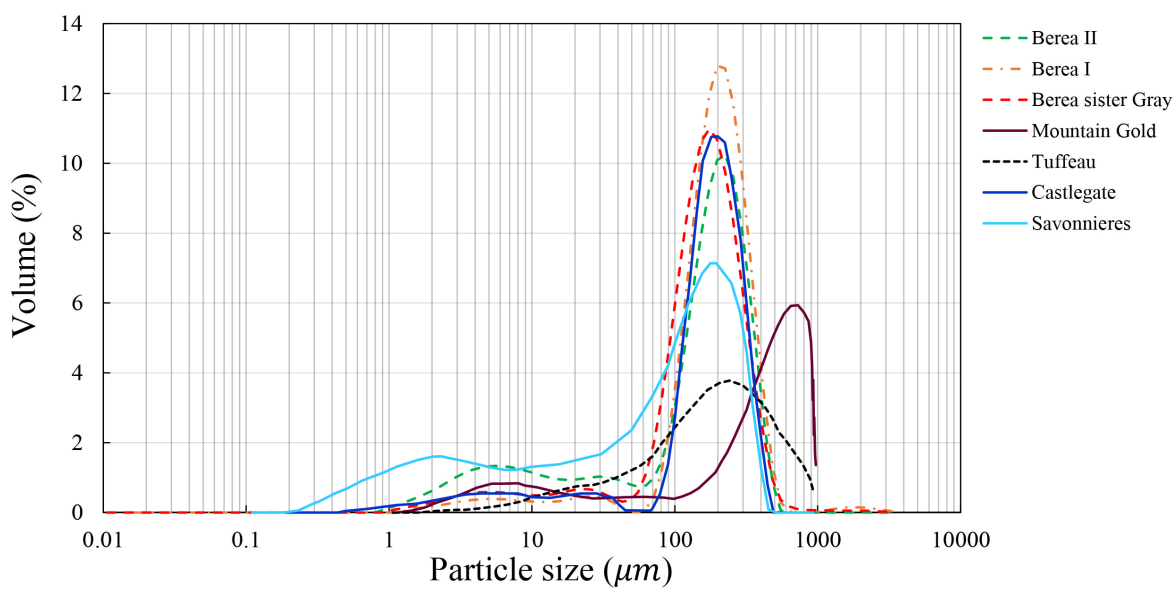

(b)

Fig. 23: Grain-size distribution of the rock samples. 
AP-608 Automated Porosimeter-Permeameter was used to measure the permeability and the porosity of the rock samples, see Fig. 24. This equipment measures porosity and permeability of cylindrical core samples using an inert gas (either helium or nitrogen). It uses the principle of gas expansion, as described by Boyle's law. A known volume (reference cell volume) of gas, at a predetermined pressure, is isothermally expanded into a sample chamber. After expansion, the resulted equilibrium pressure is measured. This pressure depends on the volume of the sample chamber minus the rock grain volume, and then the porosity can be calculated. The rock permeability is also measured through the pulse decay method.

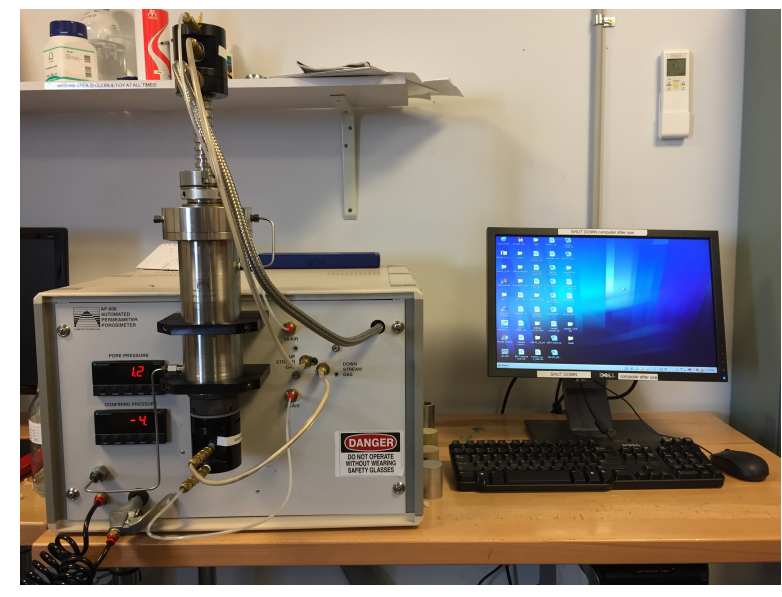

Fig. 24: AP-608 Automated Porosimeter-Permeameter.

A Sanchez Technologies tri-axial rig was used to measure the internal friction angles of two rock samples (Tuffeau and Mountain Gold). This apparatus is able to reach $150 \mathrm{MPa}$ confining pressure around cylindrical samples while the axial load is applied via a mobile piston. These two parameters are controlled separately using LabVIEW program during the experiment. The radial deformation is recorded via a Cantilever sensor (C-ring) that is fixed to the membrane via a screw and the axial deformation is recorded with 3 LVDTs. It is possible to add up to 20 sensors on 4 plans on the sample, inject fluid (oil, water) and heat the sample during the experiment. The magnitude of internal friction angle $(\varphi)$ is obtained through the slope of tangential line to the Mohr circles at the confining pressures of $2,2.5$ and $5 \mathrm{MPa}$ for Tuffeau limestone and 5,10 and $15 \mathrm{MPa}$ for Mountain Gold sandstone. The plots of shear stress as a function of normal stress are presented in Fig. 25 and 26. 


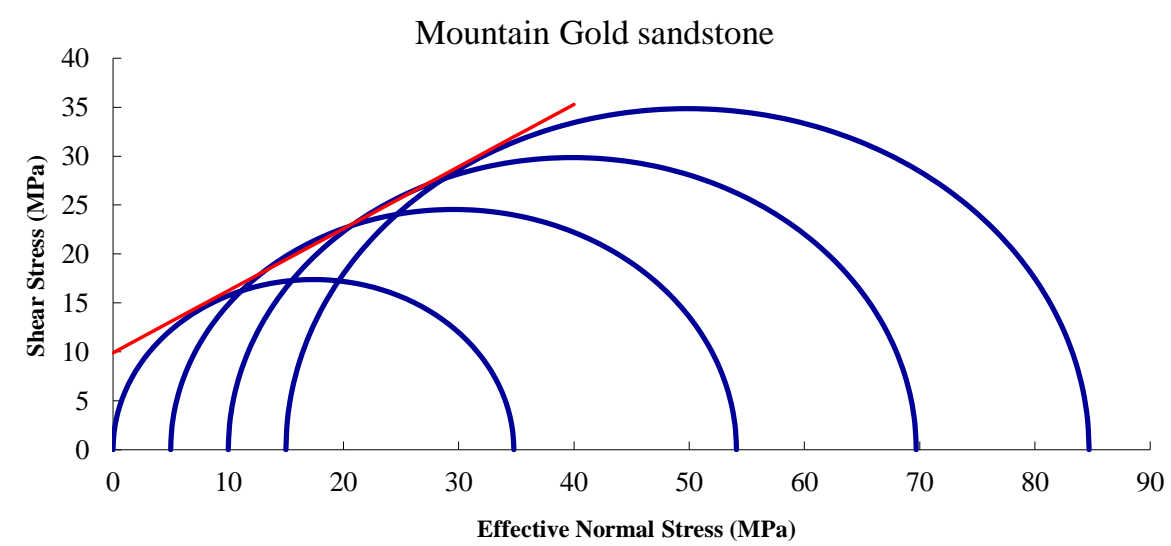

Fig. 25: Plot of shear stress versus effective normal stress. Tests conducted on Mountain Gold sandstone.

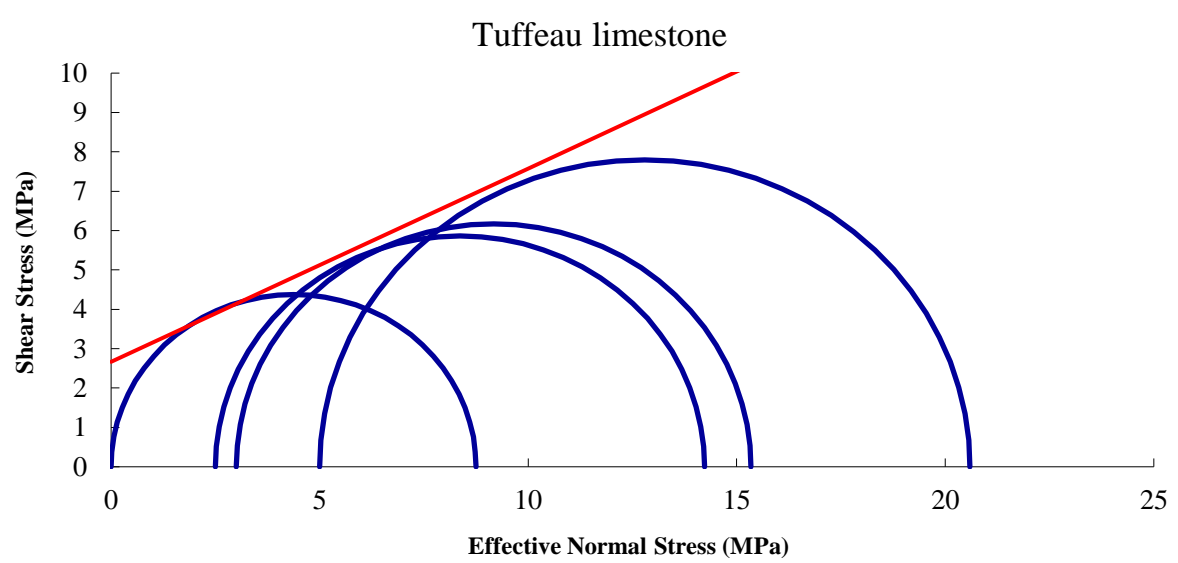

Fig. 26: Plot of shear stress versus effective normal stress. Tests conducted on Tuffeau limestone.

\section{References}

1. Adachi JI (1996) Frictional contact in rock cutting with blunt tools. M. Sc Thesis, Civil Engineering, University of Minnesota

2. Adachi JI, Detournay E, Drescher A (1996) Determination of rock strength parameters from cutting tests. Proc NARMS pp 1517-1523

3. Akbari B, Miska S (2016) The effects of chamfer and back rake angle on PDC cutters friction. Journal of Natural Gas Science and Engineering 35:347-353, DOI https://doi. org/10.1016/j.jngse.2016.08.043 
4. Akbari B, Miska SZ (2017) Relative significance of multiple parameters on the mechanical specific energy and frictional responses of polycrystalline diamond compact cutters. Journal of Energy Resources Technology 139(2):022,904, DOI 10.1115/1.4034291

5. Alehossein H, Detournay E, Huang H (2000) An analytical model for the indentation of rocks by blunt tools. Rock Mechanics and Rock Engineering 33(4):267-284, DOI $10.1007 / \mathrm{s} 006030070003$

6. Almenara J, Detournay E (1992) Cutting experiments in sandstones with blunt PDC cutters. Rock Characterization: ISRM Symposium, Eurock'92, Chester, UK, 14-17 September 1992, Thomas Telford Publishing, pp 215-220

7. Bellin F, Dourfaye A, King W, Thigpen M (2010) The current state of PDC bit technology. World oil 231(9)

8. Besselink B (2008) Analysis and validation of self-excited drill string oscillations. M. Sc Thesis, Department of Mechanical Engineering, Eindhoven University of Technology

9. Challamel N, Sellami H (1998) Application of yield design for understanding rock cutting mechanism. SPE/ISRM Rock Mechanics in Petroleum Engineering, Society of Petroleum Engineers, DOI https://doi.org/10.2118/47340-MS

10. Che D, Han P, Guo P, Kornel E (2012) Issues in polycrystalline diamond compact cutter-rock interaction from a metal machining point of view-part i: Temperature, stresses, and forces. Journal of Manufacturing Science and Engineering 134(6), DOI http://dx.doi.org/10.1115/1.4007468

11. Che D, Zhu WL, Ehmann KF (2016) Chipping and crushing mechanisms in orthogonal rock cutting. International Journal of Mechanical Sciences 119:224-236, DOI https: //doi.org/10.1016/j.ijmecsci.2016.10.020

12. Cheatham CA, Loeb DA (1985) Effects of field wear on PDC bit performance. SPE/IADC Drilling Conference, 5-8 March, New Orleans, Louisiana, Society of Petroleum Engineers, DOI 10.2118/13464-MS

13. Chen LH, Labuz JF (2006) Indentation of rock by wedge-shaped tools. International Journal of Rock Mechanics and Mining Sciences 43(7):1023-1033, DOI https://doi.org/ 10.1016/j.ijrmms.2006.03.005

14. Coudyzer C, Richard T (2005) Influence of the back and side rake angles in rock cutting. AADE 2005 National Technical Conference and Exhibition, Wyndam Greenspoint, Houston, TX, April, pp 5-7

15. Dagrain F (2006) Etude des mecanismes de coupe des roches avec couteaux uses approche des mécanismes de frottement sous les couteaux par le concept du troisième corps. Ph.D Thesis, Faculté Polytechnique de Mons

16. Dagrain F, Detournay E, Richard T (2001) Influence of cutter geometry in rock cutting. DC Rocks 2001, The 38th US Symposium on Rock Mechanics (USRMS), American Rock Mechanics Association

17. Detournay E, Defourny P (1992) A phenomenological model for the drilling action of drag bits. International Journal of Rock Mechanics and Mining Sciences \& Geomechanics Abstracts 29(1):13-23, DOI https://doi.org/10.1016/0148-9062(92)91041-3

18. Detournay E, Richard T, Shepherd M (2008) Drilling response of drag bits: Theory and experiment. International Journal of Rock Mechanics and Mining Sciences 45(8):13471360, DOI http://dx.doi.org/10.1016/j.ijrmms.2008.01.010

19. Fairhurst C, Lacabanne W (1957) Hard rock drilling techniques. Mine Quarry Eng 23:157-161

20. Geoffroy H (1996) Etude de l'interaction roche/outil de forage: Influence de l'usure sur les parametres de coupe. Ph. D. Thesis, Ecole Polytechique Paris

21. Geoffroy H, Minh DN (1997) Study on interaction between rocks and worn PDC's cutter International Journal of Rock Mechanics and Mining Sciences 34(3-4):95e1-95e15, DOI https://doi.org/10.1016/S1365-1609(97)00036-1

22. Gerbaud L, Menand S, Sellami H (2006) PDC bits: All comes from the cutter rock interaction. IADC/SPE Drilling Conference, 21-23 February, Miami, Florida, USA, Society of Petroleum Engineers, DOI http://dx.doi.org/10.2118/98988-MS

23. Glowka DA (1987) Development of a method for predicting the performance and wear of PDC (polycrystalline diamond compact) drill bits. Tech. rep., Sandia National Labs., Albuquerque, NM (USA) 
24. Glowka DA (1989) Use of single-cutter data in the analysis of PDC bit designs: Part 1-development of a PDC cutting force model. Journal of Petroleum Technology 41(08):797-849, DOI https://doi.org/10.2118/15619-PA

25. Hood M, Alehossein H (2000) A development in rock cutting technology. International journal of rock mechanics and mining sciences 37(1):297-305, DOI https://doi.org/10. 1016/S1365-1609(99)00107-0

26. Huang H, Damjanac B, Detournay E (1997) Numerical modeling of normal wedge indentation in rocks with lateral confinement. International Journal of Rock Mechanics and Mining Sciences 34(3-4):64.e1-64.e15, DOI https://doi.org/10.1016/S1365-1609(97) 00169-X

27. Huang H, Damjanac B, Detournay E (1998) Normal wedge indentation in rocks with lateral confinement. Rock Mechanics and Rock Engineering 31(2):81-94, DOI https: //doi.org/10.1007/s006030050010

28. Johnson KL (1985) Contact mechanics. Cambridge University Press, U.K

29. Kalantari S, Hashemolhosseini H, Baghbanan A (2018) Estimating rock strength parameters using drilling data. International Journal of Rock Mechanics and Mining Sciences 104:45-52, DOI https://doi.org/10.1016/j.ijrmms.2018.02.013

30. Lasserre C (1994) Rock friction apparatus: Realisation de tests de coupe sur roches a l'aide d'un outil PDC. Tech. rep., Institut en Sciences et Technologies Geophysique et Geotechniques, Universite de Paris VI, Paris, France

31. Lhomme T (1999) Frictional contact at a rock-tool interface: An experimental study. M. Sc Thesis, University of Minnesota

32. Li XB, Summers DA, Rupert G, Santi P (2001) Experimental investigation on the breakage of hard rock by the PDC cutters with combined action modes. Tunnelling and Underground Space Technology 16(2):107-114, DOI https://doi.org/10. 1016/S0886-7798(01)00036-0

33. Liu H, Kou S, Lindqvist PA (2002) Numerical simulation of the fracture process in cutting heterogeneous brittle material. International journal for numerical and analytical methods in geomechanics 26(13):1253-1278, DOI http://dx.doi.org/10.1002/nag.243

34. Liu W, Zhu X, Jing J (2018) The analysis of ductile-brittle failure mode transition in rock cutting. Journal of Petroleum Science and Engineering 163:311 - 319, DOI https://doi.org/10.1016/j.petrol.2017.12.067

35. Menand S, Gerbaud L, Dourfaye A (2005) PDC bit technology improvements increase efficiency, bit life. Drilling Contractor pp 52-54, URL https://hal-mines-paristech. archives-ouvertes.fr/hal-00584232

36. Mensa-Wilmot G (2013) Impact resistant PDC drill bit. US Patent 8,448,725

37. Naeimipour A, Rostami J (2017) Estimation of rock in-situ strength using rock strength borehole probe (rsbp). 51st US Rock Mechanics/Geomechanics Symposium, American Rock Mechanics Association

38. Perneder L, Detournay E, Downton G (2012) Bit/rock interface laws in directional drilling. International Journal of Rock Mechanics and Mining Sciences 51:81-90, DOI https://doi.org/10.1016/j.ijrmms.2012.01.008

39. Richard T (1999) Determination of rock strength from cutting tests. M. Sc Thesis, Faculty of the Graduate School of the University of Minnesota, Minneapolis, Minnesota, U.S.A.

40. Richard T, Detournay E, Drescher A, Nicodeme P, Fourmaintraux D (1998) The scratch test as a means to measure strength of sedimentary rocks. SPE/ISRM Eurock 98, Society of Petroleum Engineers, Trondheim, Norway, SPE 47196, pp 1-8, DOI 10.2118/47196-MS

41. Richard T, Coudyzer C, Desmette S (2010) Influence of groove geometry and cutter inclination in rock cutting. 44th US Rock Mechanics Symposium and 5th US-Canada Rock Mechanics Symposium, American Rock Mechanics Association

42. Richard T, Dagrain F, Poyol E, Detournay E (2012) Rock strength determination from scratch tests. Engineering Geology 147-148:91-100, DOI http://dx.doi.org/10.1016/j. enggeo.2012.07.011

43. Rostam Sowlat I (2017) Effect of cutter and rock properties on the frictional contact in rock cutting with blunt tools. PhD thesis, Curtin University 
44. Rostamsowlat I (2018) Effect of cutting tool properties and depth of cut in rock cutting: An experimental study. Rock Mechanics and Rock Engineering pp 1-14, DOI https: //doi.org/10.1007/s00603-018-1440-2

45. Rostamsowlat I, Richard T, Evans B (2018) An experimental study of the effect of back rake angle in rock cutting. International Journal of Rock Mechanics and Mining Sciences In press

46. Theodoridou M, Dagrain F, Ioannou I (2015) Micro-destructive cutting techniques for the characterization of natural limestone. International Journal of Rock Mechanics and Mining Sciences (76):98-103, DOI https://doi.org/10.1016/j.ijrmms.2015.02.012

47. Warren TM, Sinor LA (1994) PDC bits: what's needed to meet tomorrow's challenge. University of Tulsa Centennial Petroleum Engineering Symposium, 29-31 August, Tulsa, Oklahoma, Society of Petroleum Engineers

48. Wojtanowicz A, Kuru E (1993) Mathematical modeling of PDC bit drilling process based on a single-cutter mechanics. Journal of Energy Resources Technology 115(4):247256, DOI doi:10.1115/1.2906429

49. Xiao Y, Hurich C, Butt SD (2018) Assessment of rock-bit interaction and drilling performance using elastic waves propagated by the drilling system. International Journal of Rock Mechanics and Mining Sciences 105:11-21, DOI https://doi.org/10.1016/j.ijrmms. 2018.02.006

50. Yadav S, Saldana C, Murthy TG (2018) Experimental investigations on deformation of soft rock during cutting. International Journal of Rock Mechanics and Mining Sciences 105:123-132, DOI https://doi.org/10.1016/j.ijrmms.2018.03.003

51. Zhou Y, Detournay E (2014) Analysis of the contact forces on a blunt PDC bit. 48th US Rock Mechanics / Geomechanics Symposium, ARMA, ARMA 14-7351

52. Zhou Y, Lin JS (2013) On the critical failure mode transition depth for rock cutting. International Journal of Rock Mechanics and Mining Sciences 62:131-137, DOI http: //dx.doi.org/10.1016/j.ijrmms.2013.05.004

53. Zhou Y, Lin JS (2014) Modeling the ductile-brittle failure mode transition in rock cutting. Engineering Fracture Mechanics 127:135 - 147, DOI http://dx.doi.org/10.1016/ j.engfracmech.2014.05.020

54. Zhou Y, Zhang W, Gamwo I, Lin JS (2017) Mechanical specific energy versus depth of cut in rock cutting and drilling. International Journal of Rock Mechanics and Mining Sciences 100:287 - 297, DOI https://doi.org/10.1016/j.ijrmms.2017.11.004

55. Zijsling D (1984) Analysis of temperature distribution and performance of polycrystalline diamond compact bits under field drilling conditions. SPE annual technical conference and exhibition, 16-19 September, Houston, Texas, Society of Petroleum Engineers 